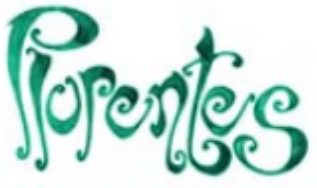

Artes y Letras
Plurentes. Artes y Letras

ISSN: 1853-6212

plurentesunlp@gmail.com

Universidad Nacional de La Plata

Secretaría de Asuntos Académicos

Prosecretaría de Asuntos Académicos

Bachillerato de Bellas Artes, "Prof. Francisco A. De Santo" Argentina

\title{
Tres piezas para viola y piano
}

Loudet, Pablo

Tres piezas para viola y piano

Plurentes. Artes y Letras, núm. 11, e015, 2020

Universidad Nacional de La Plata

Secretaría de Asuntos Académicos

Prosecretaría de Asuntos Académicos

Bachillerato de Bellas Artes, "Prof. Francisco A. De Santo"

Argentina

DOI: https://doi.org/10.24215/18536212e015

Atribución no comercial compartir igual (CC BY-NC-SA) 4.0 


\section{Tres piezas para viola y piano}

Pablo Loudet

Universidad Nacional de La Plata, Argentina ploudet@gmail.com
DOI: https://doi.org/10.24215/18536212e015

Recepción: 13 Septiembre 2020 Aprobación: 15 Septiembre 2020

Publicación: 26 Octubre 2020

Obra original para viola y piano escrita por invitación de Gabriela Martínez y Diana Gasparini, integrantes del dúo Vivalto da camera y profesoras del Bachillerato de Bellas Artes, a quienes las piezas están dedicadas. Consta de tres movimientos que podrían enmarcarse dentro del género del nacionalismo musical a partir de la mixtura entre lo académico y lo popular. Desde el punto de vista técnico está construidas en base a esquemas formales simples, texturas tradicionales, células rítmicas y giros melódicos típicos de la música argentina, armonía simétrica / disonante y la utilización de la variación y el contraste como recursos compositivos generales. 
a Gabriela Martínez y Diana Gasparini,

integrantes del dúo Vivalto da camera

\section{Tres piezas para viola y piano}

I.

Pablo Loudet

(2020)
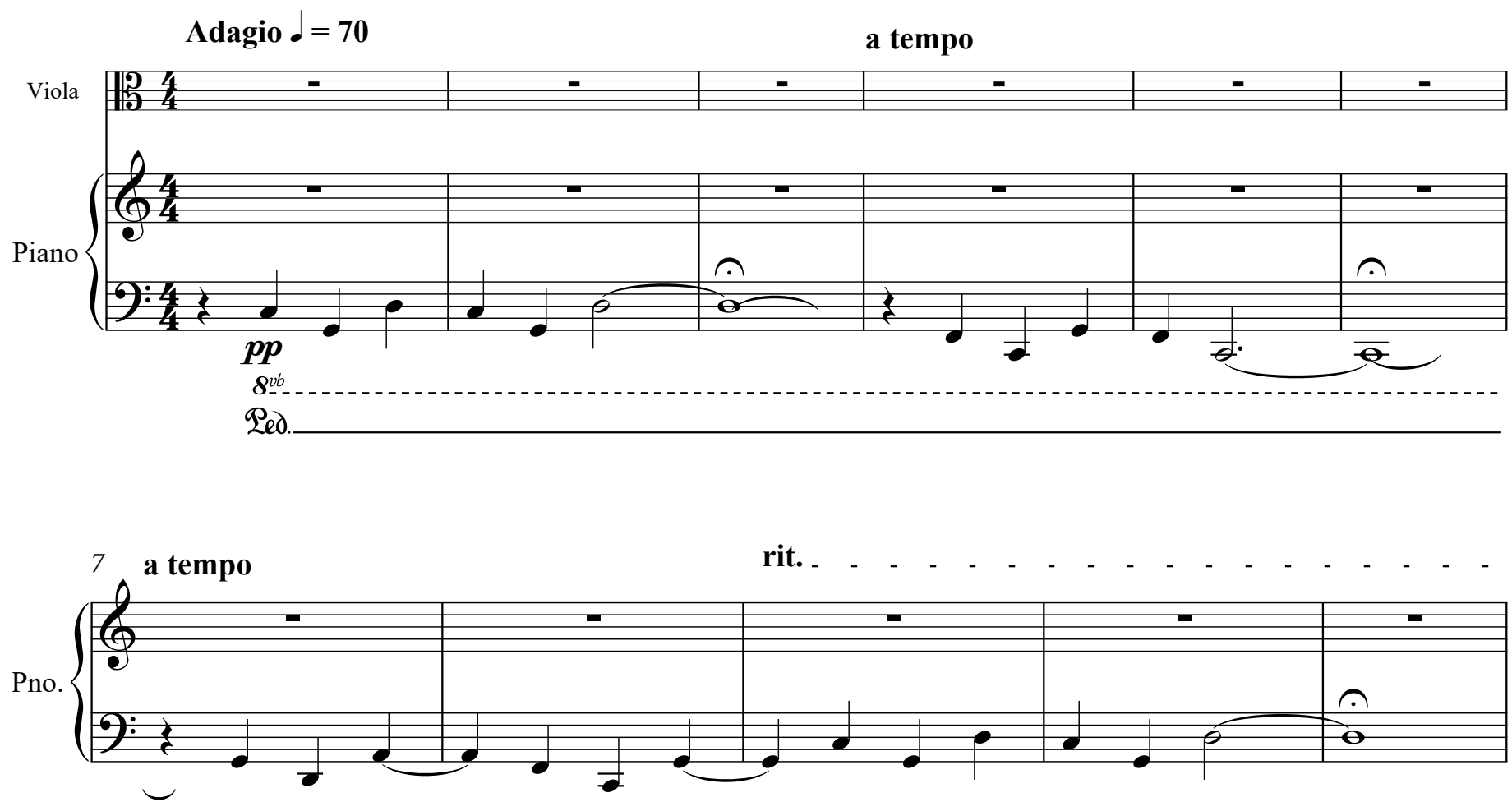

$(8)$
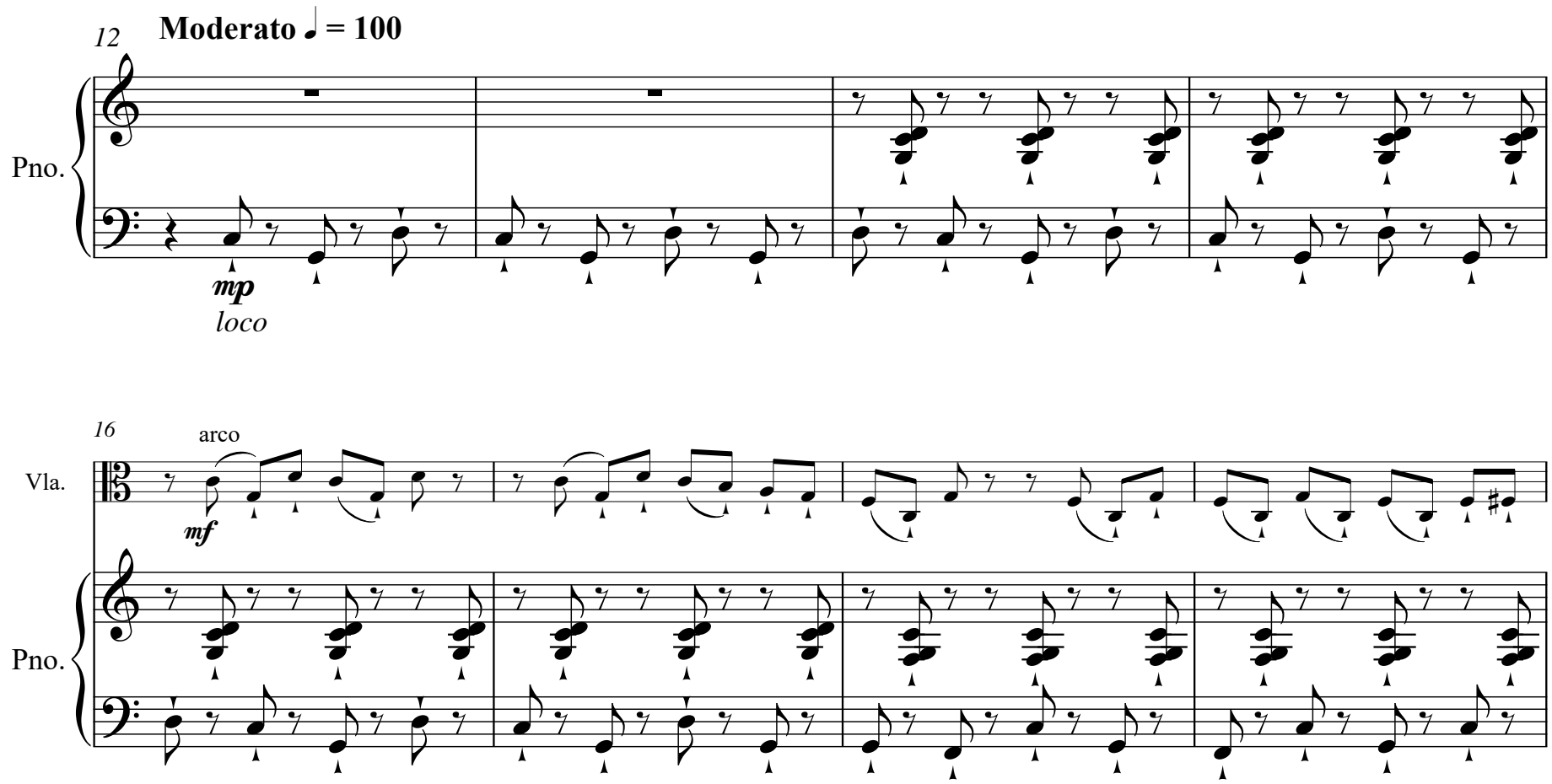

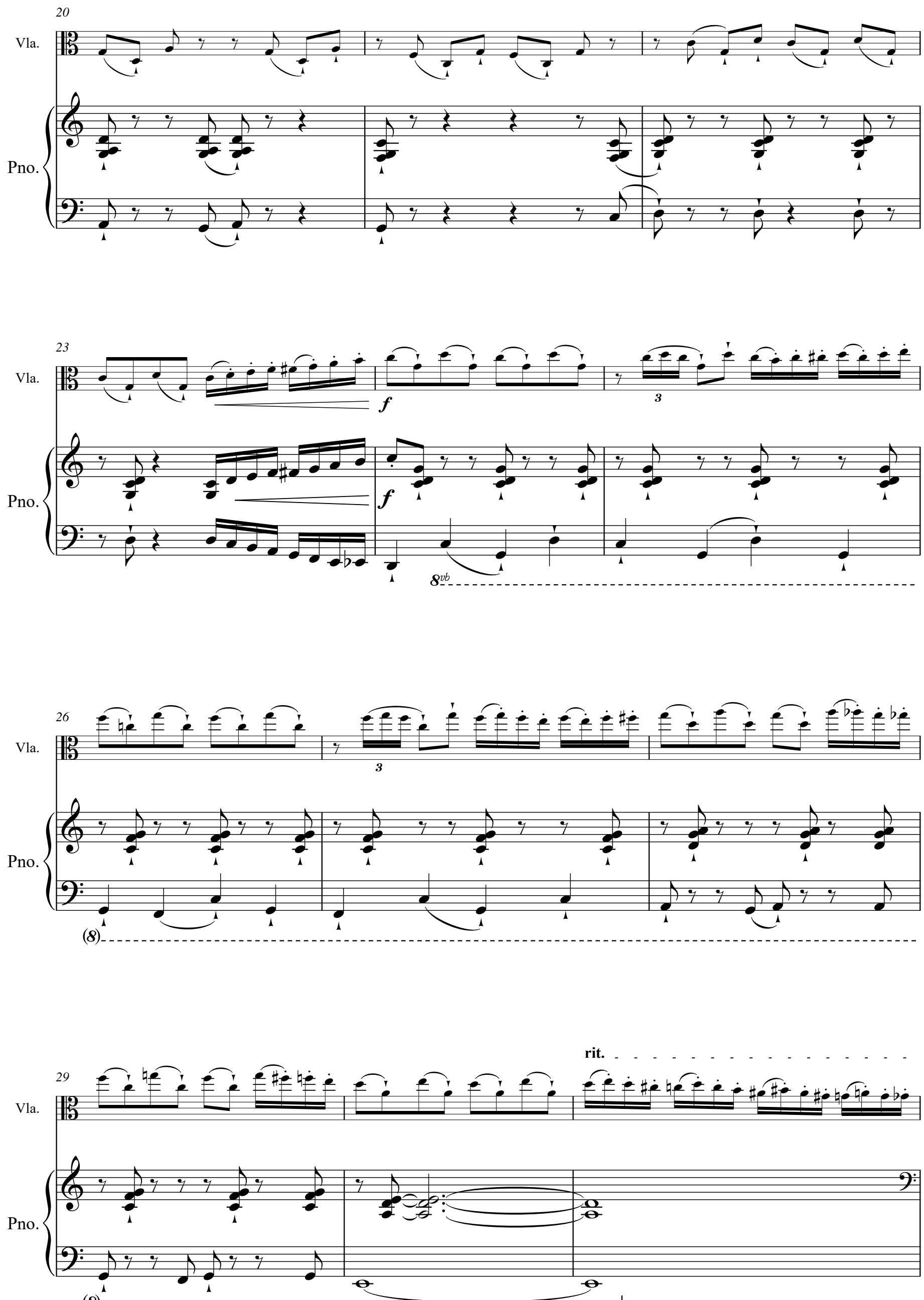

(8) 
Andante $\downarrow=80$

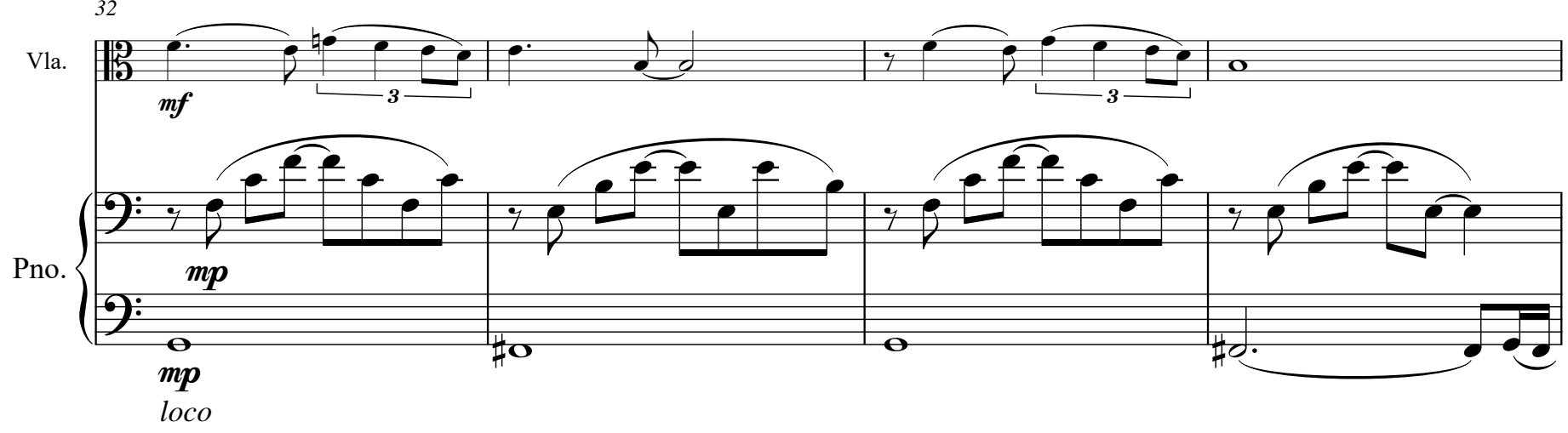

accel.
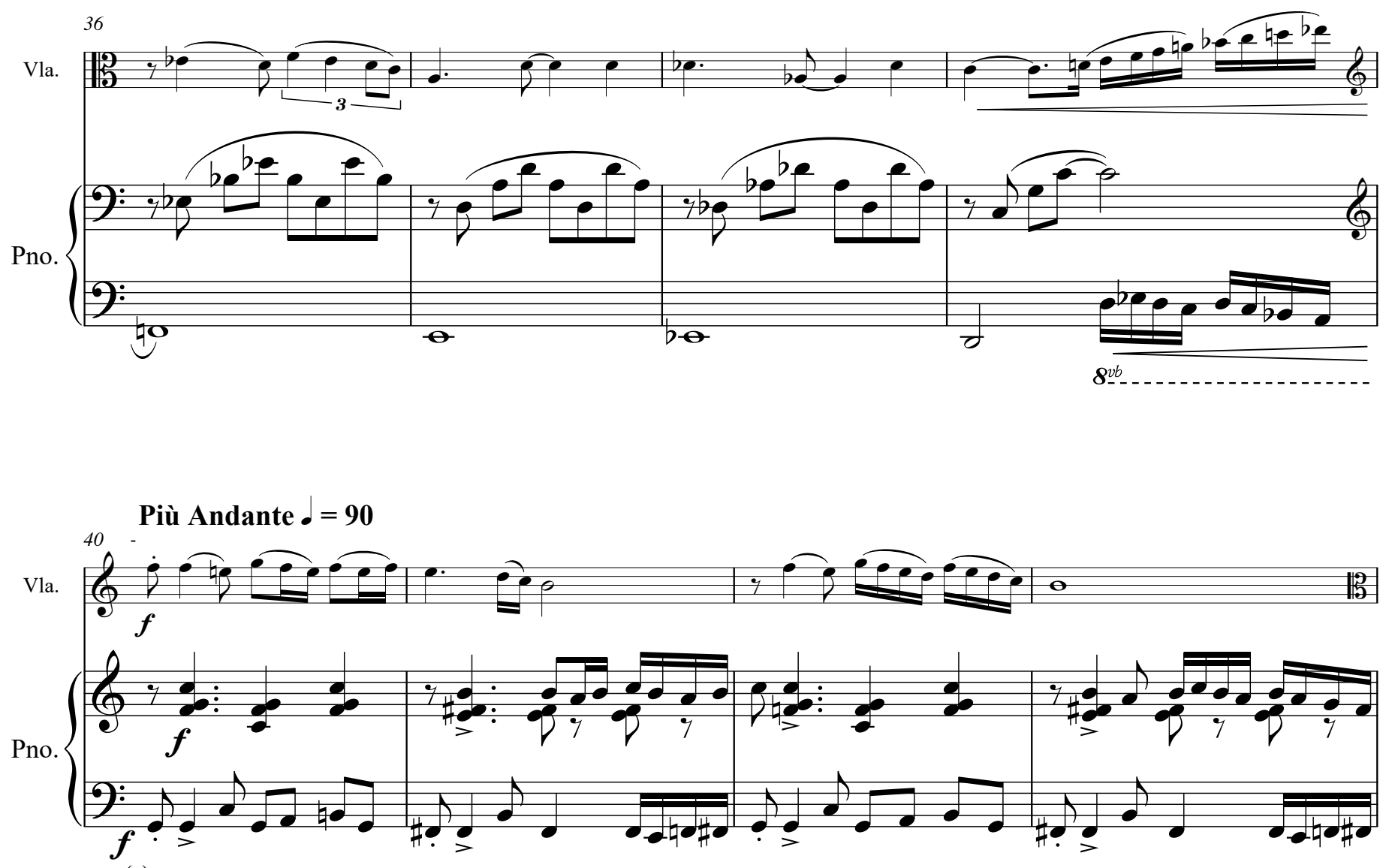

$(8)$

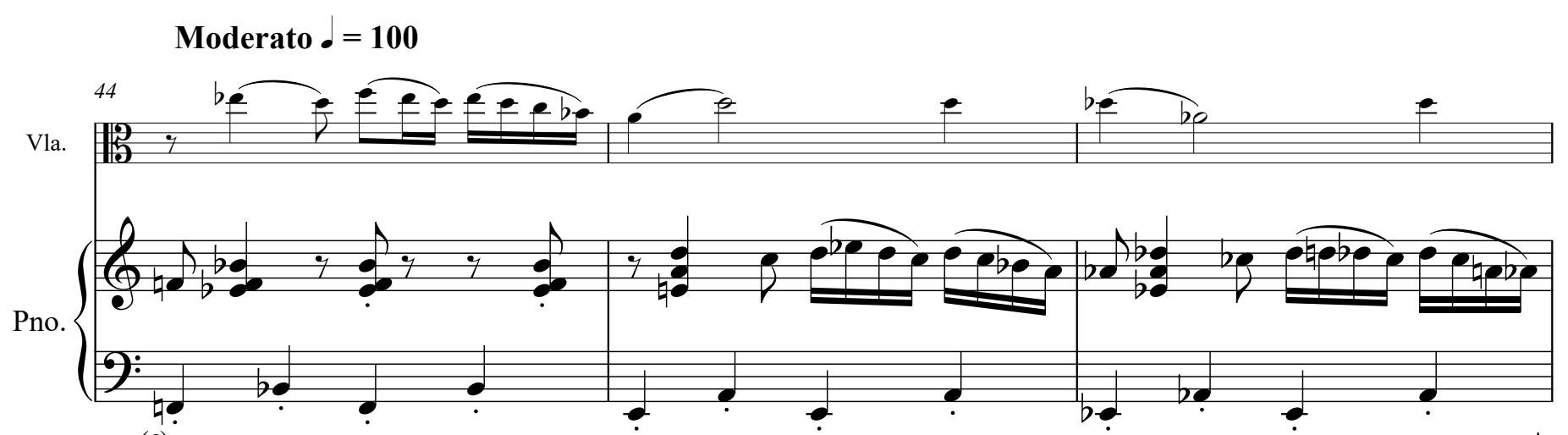

$(8)$ 
Plurentes, 2020, núm. 11, e015, ISSN: 1853-6212

4

Più Moderato $\_\mathbf{~} \mathbf{1 1 0}$
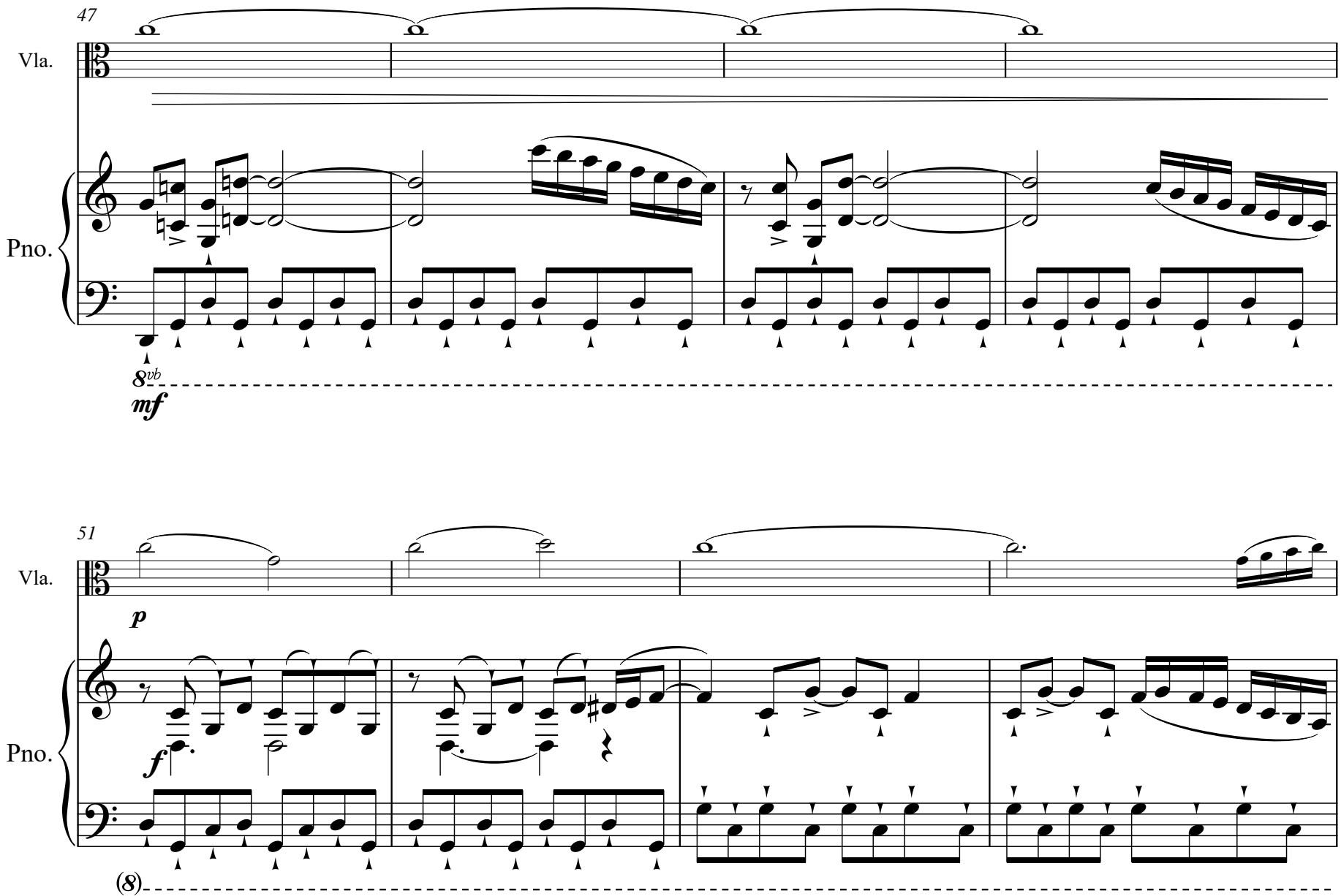

(8)
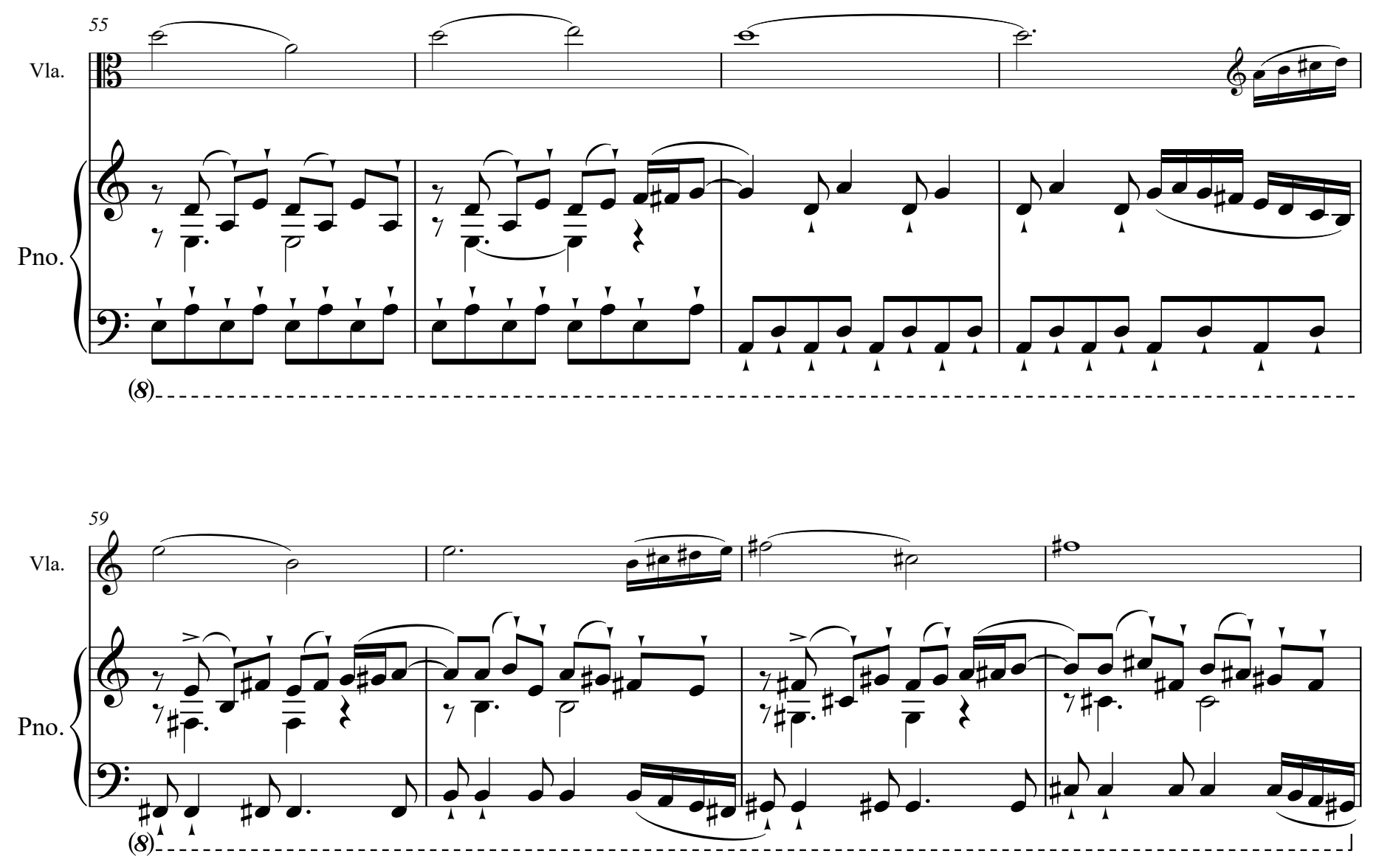

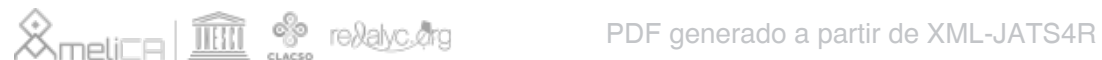

อ 


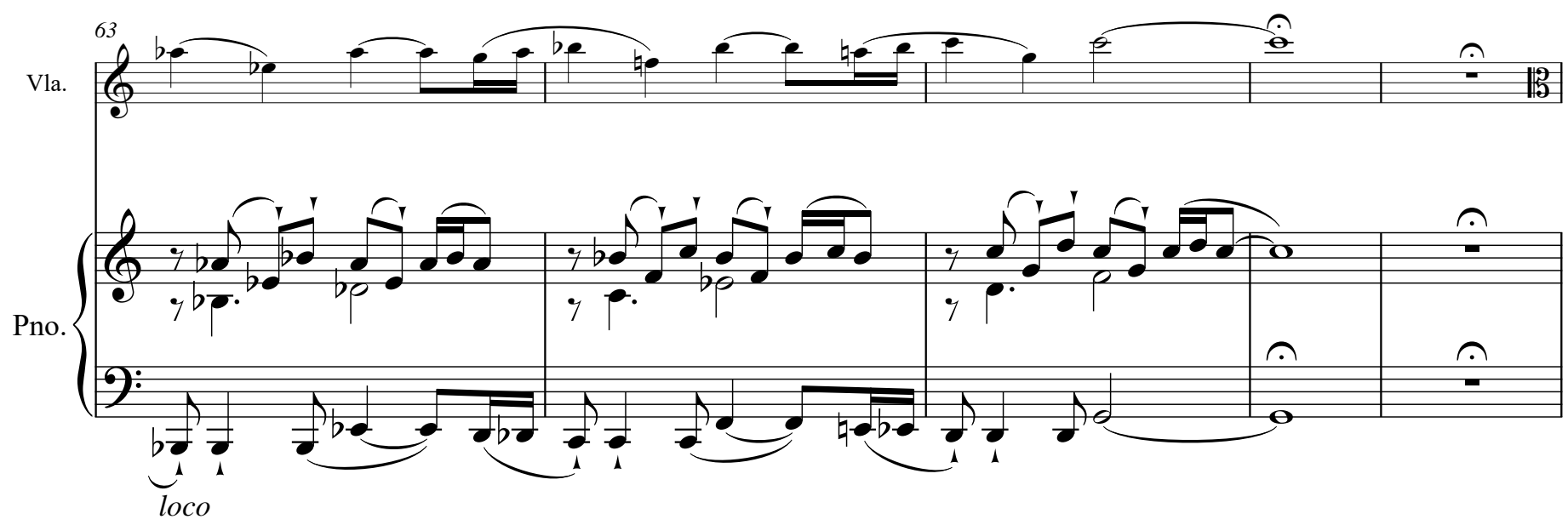

Andante $\downarrow=80$ Tempo rubato

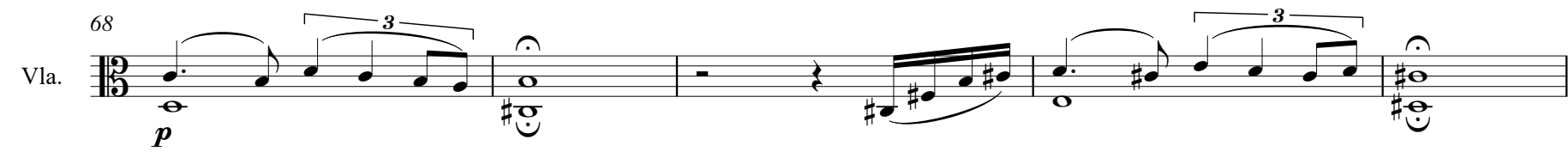
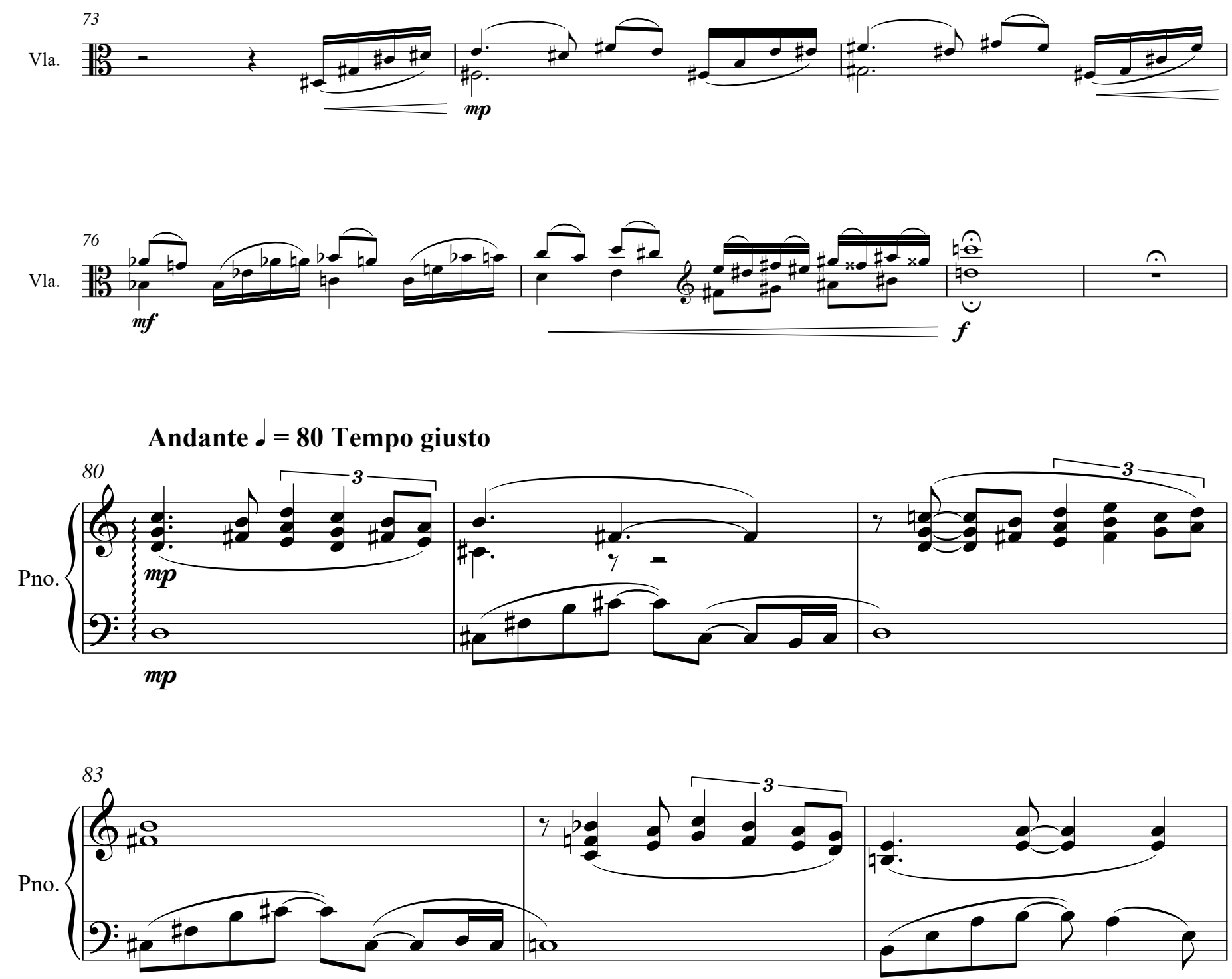
6

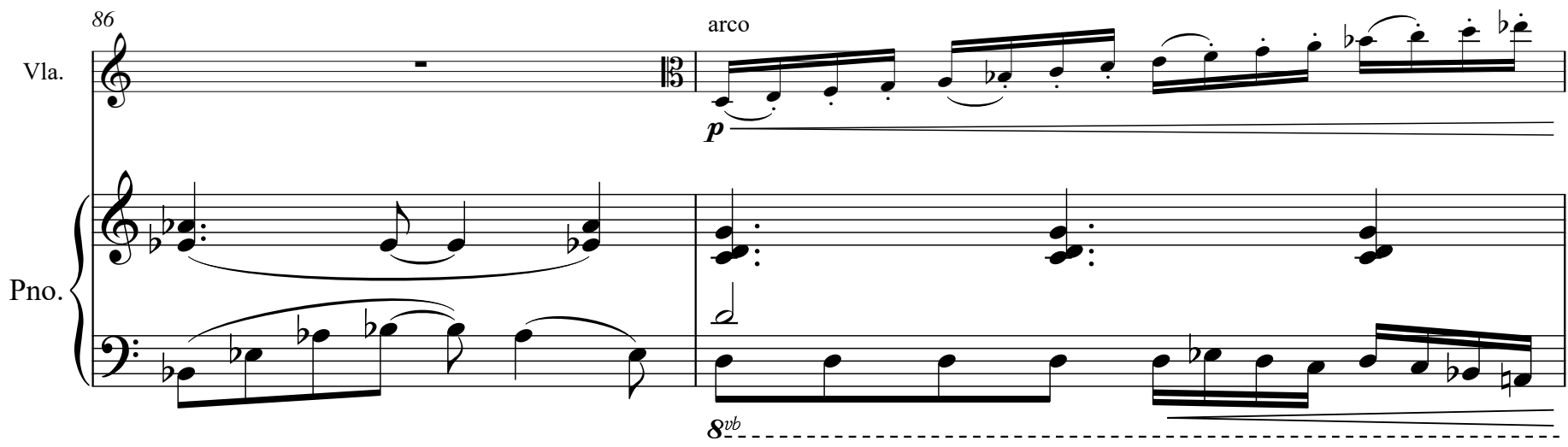

Più Andante $\bullet=90$

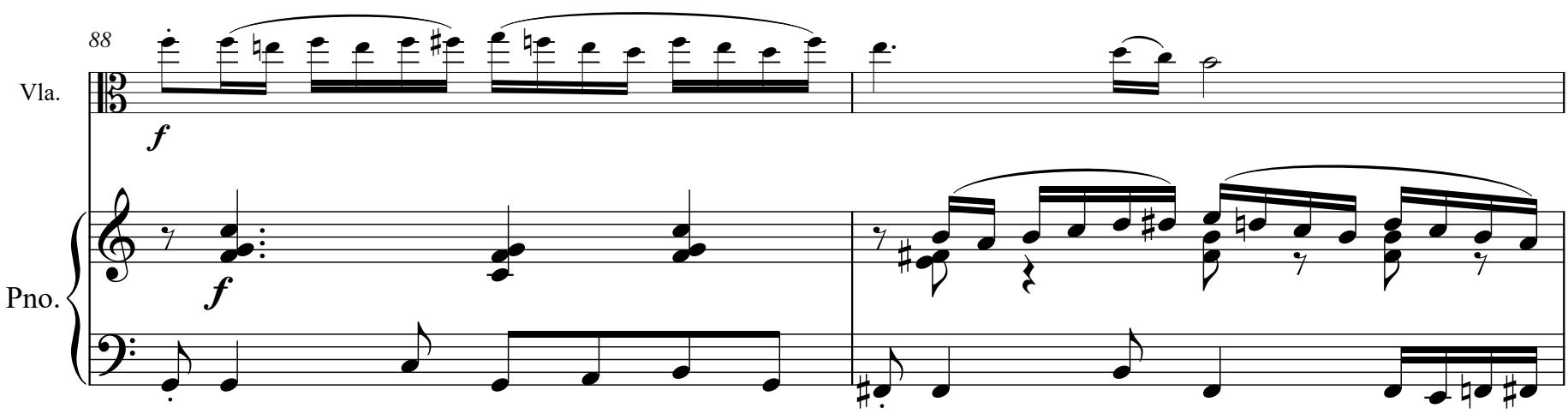

(8)

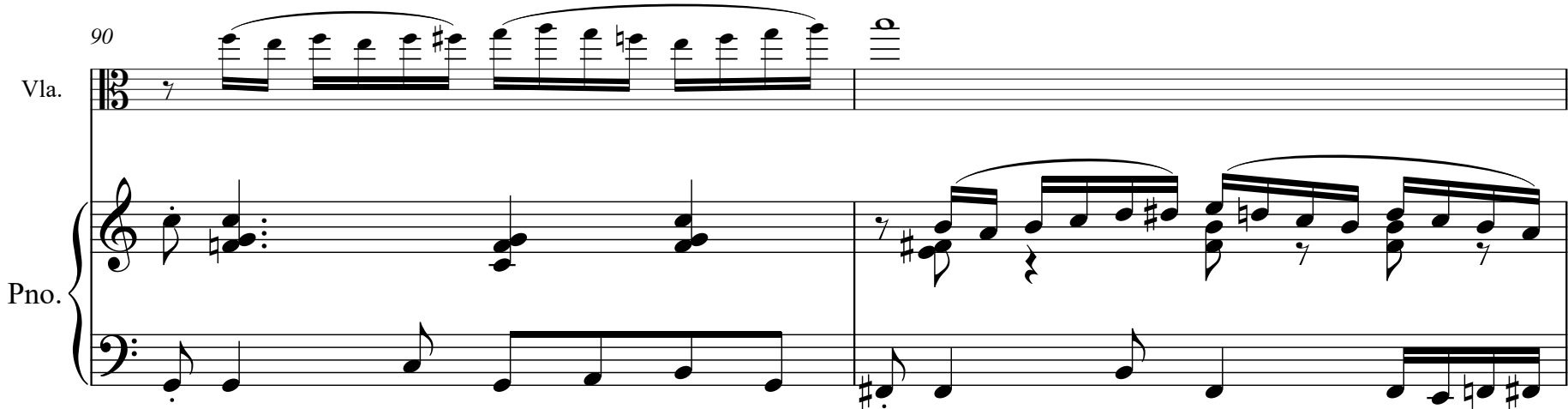

(8)

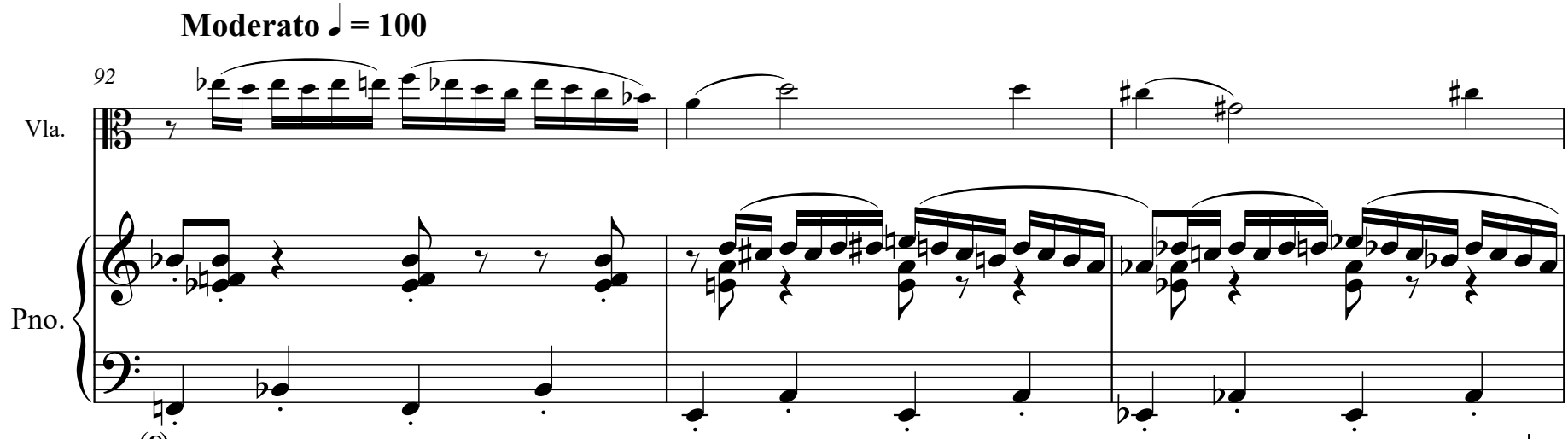

(8) 
Allegro $d=130$
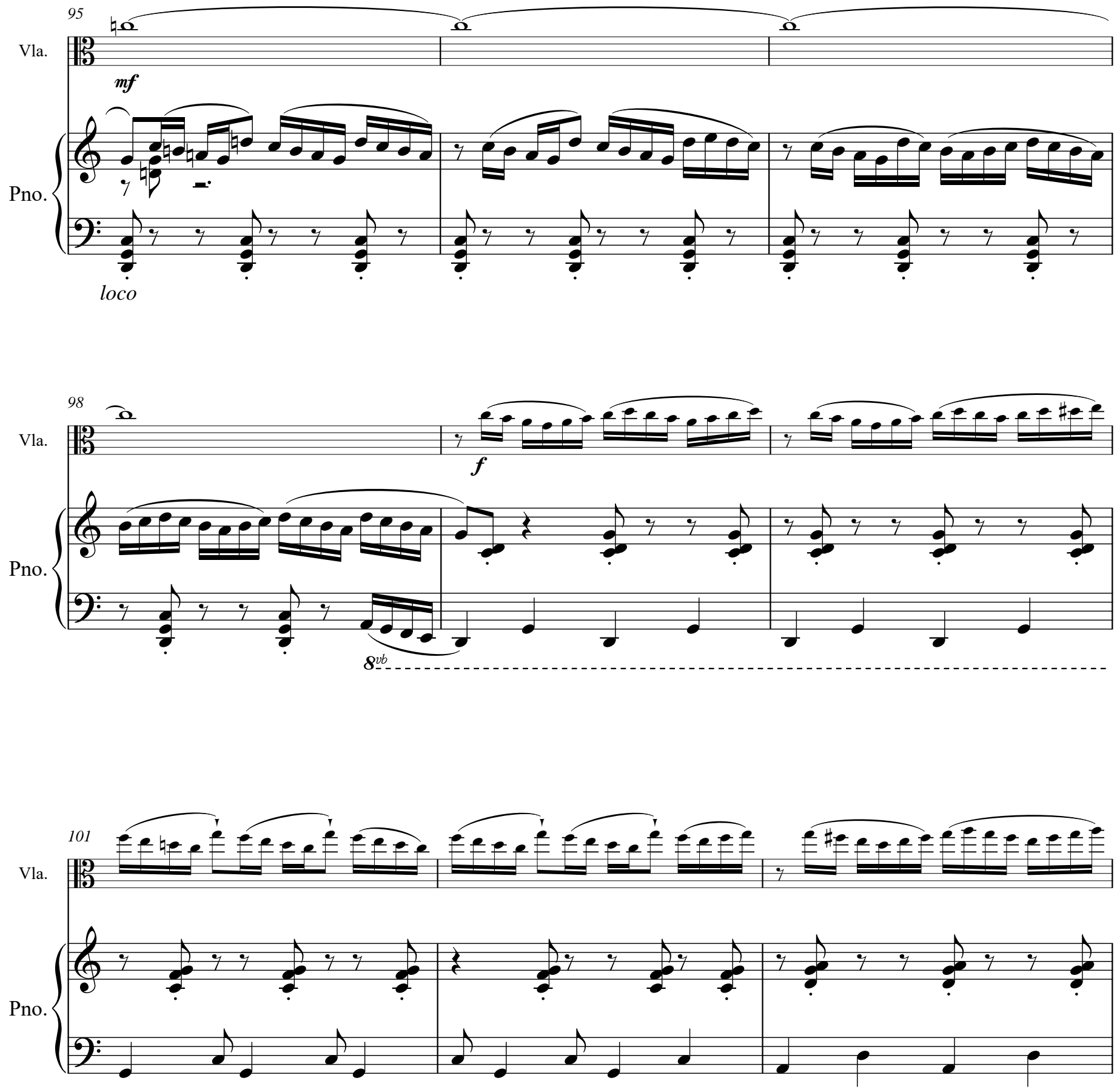

(8)

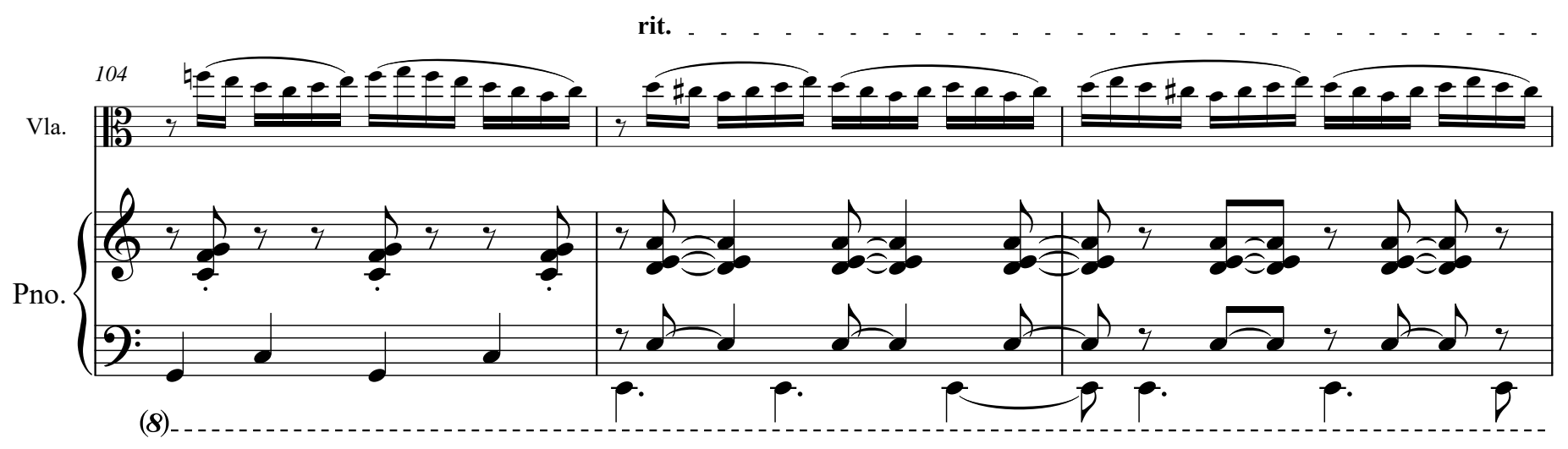


8

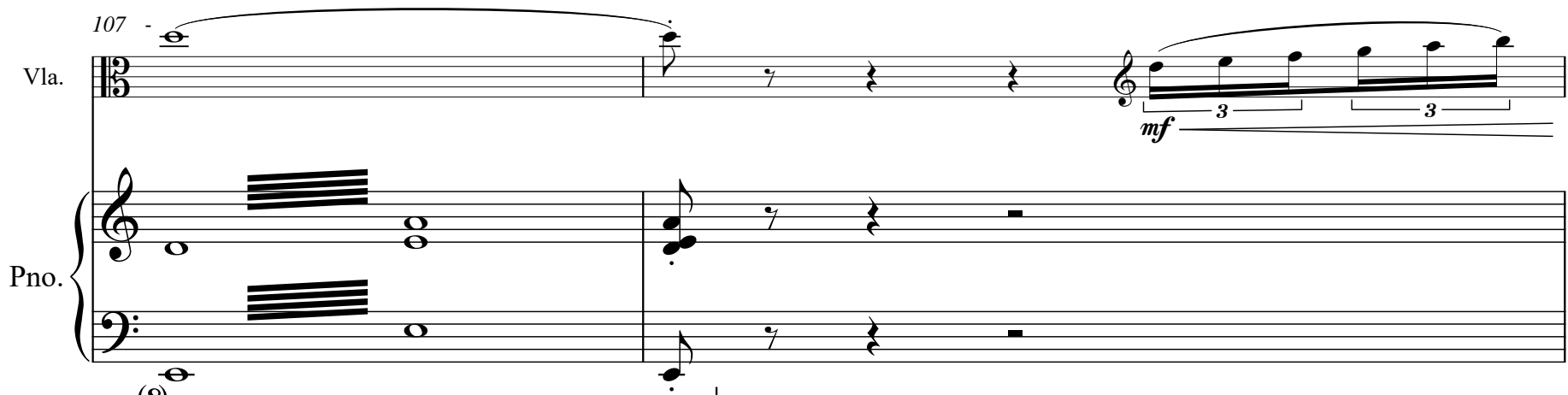

$(8)$
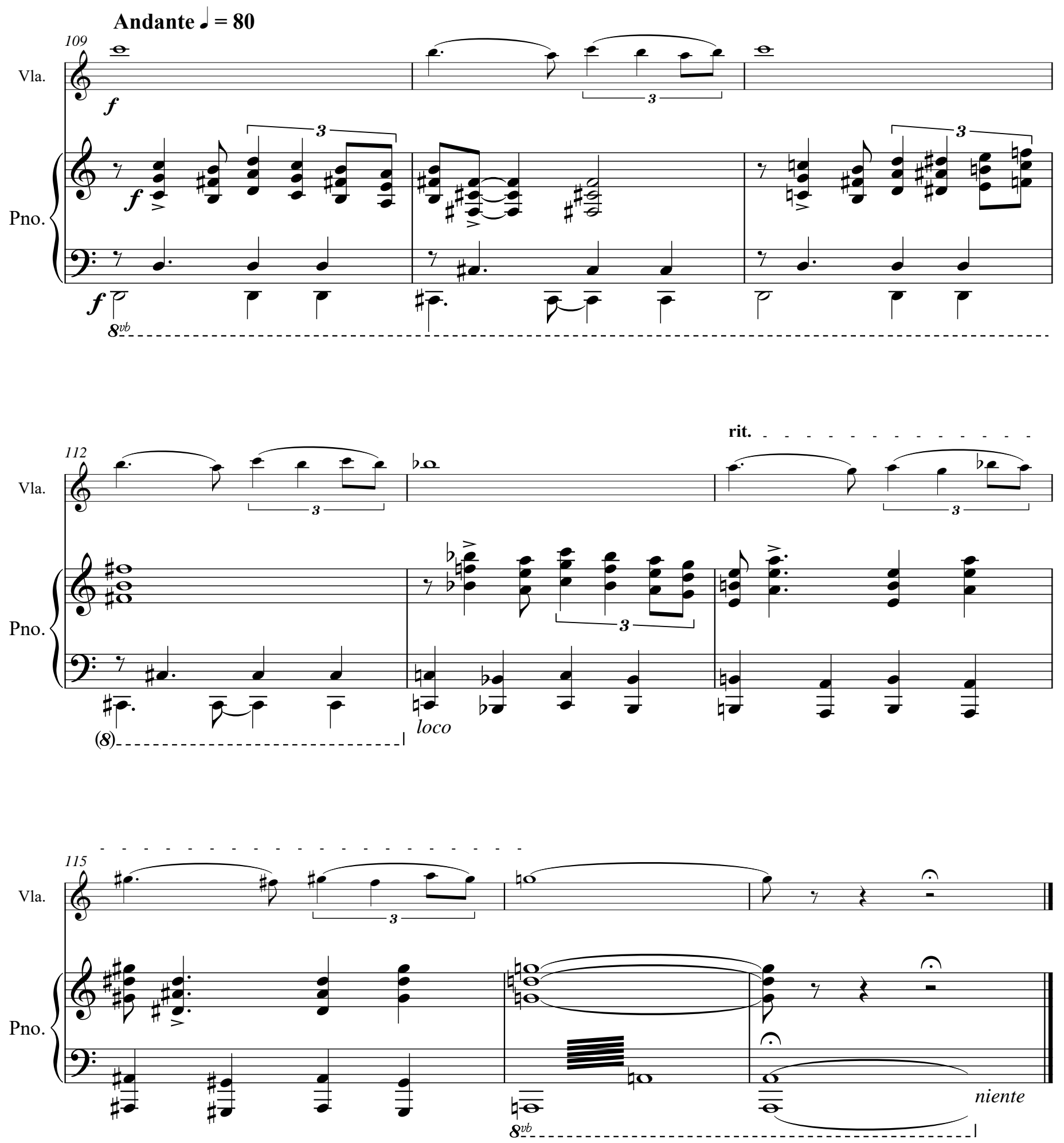
II.

Adagio $d=70$
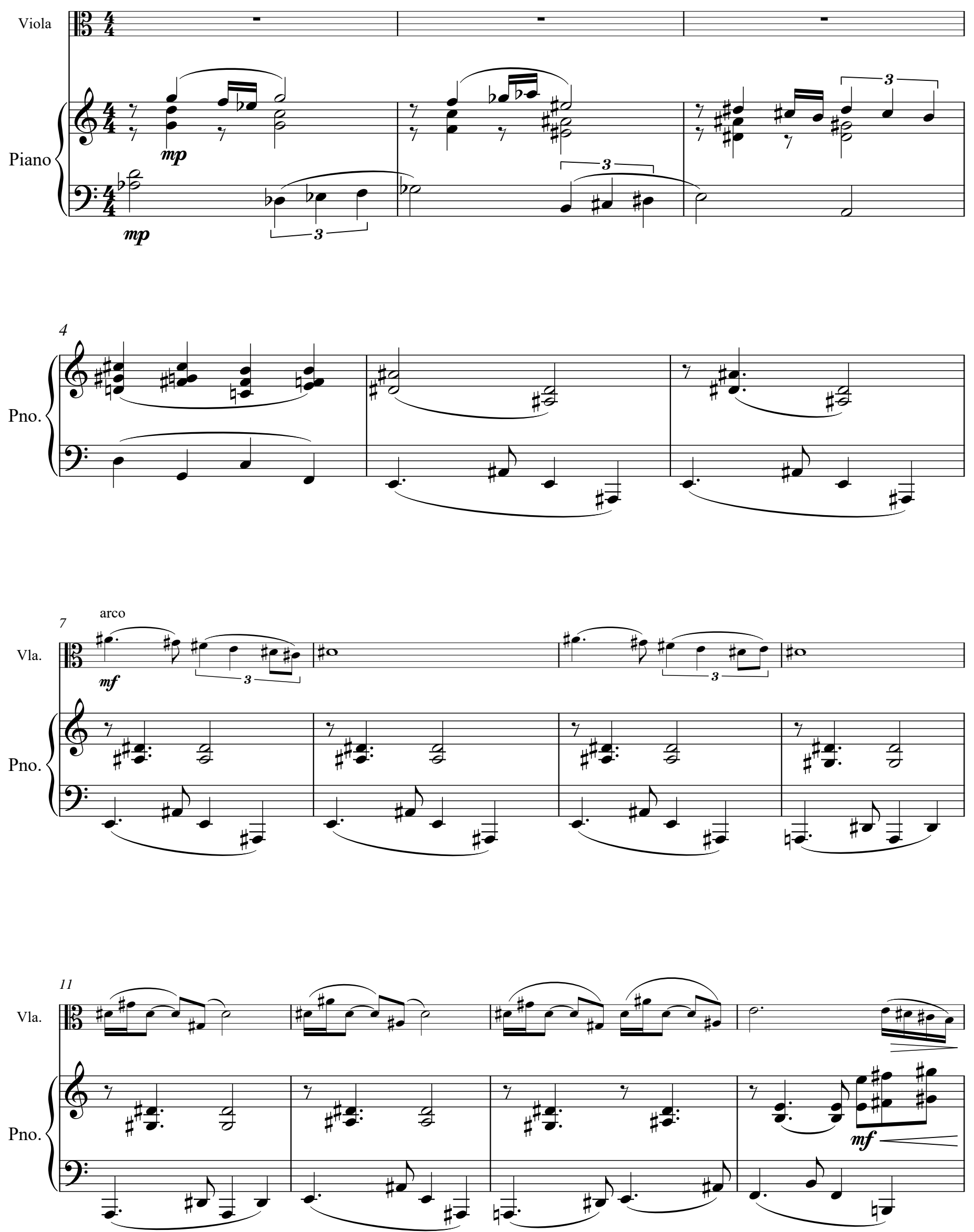
$10 \quad 15$
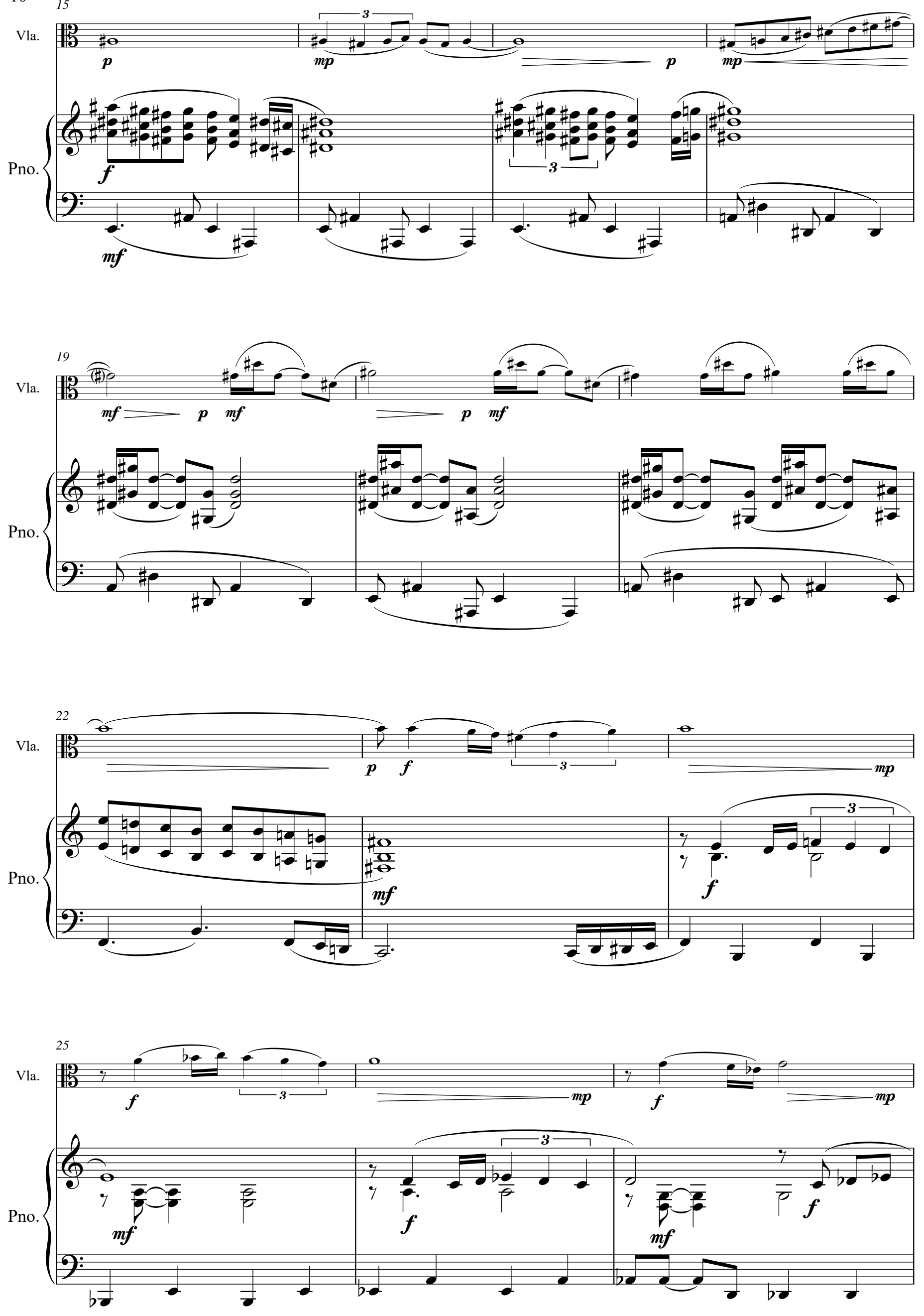

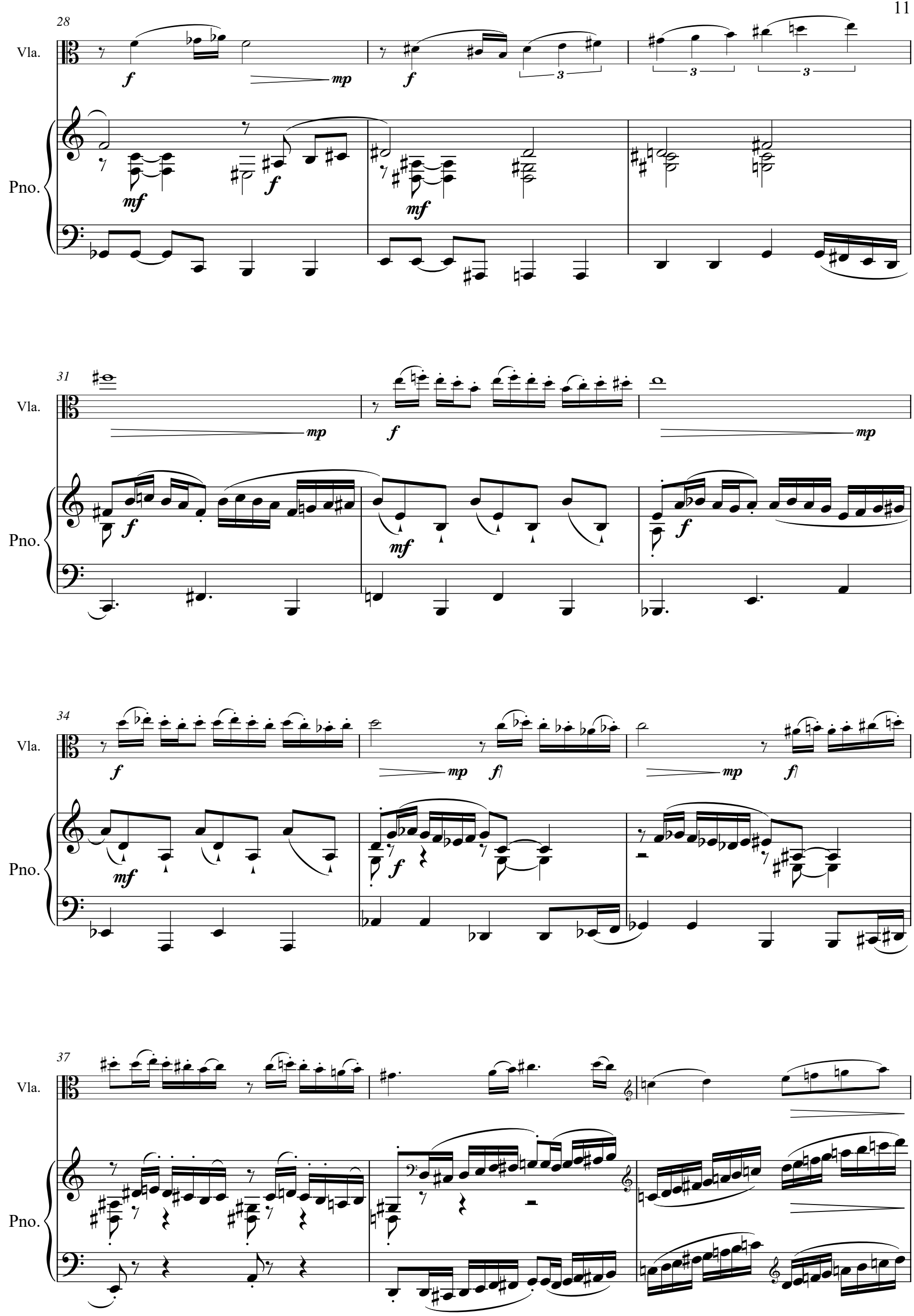
12
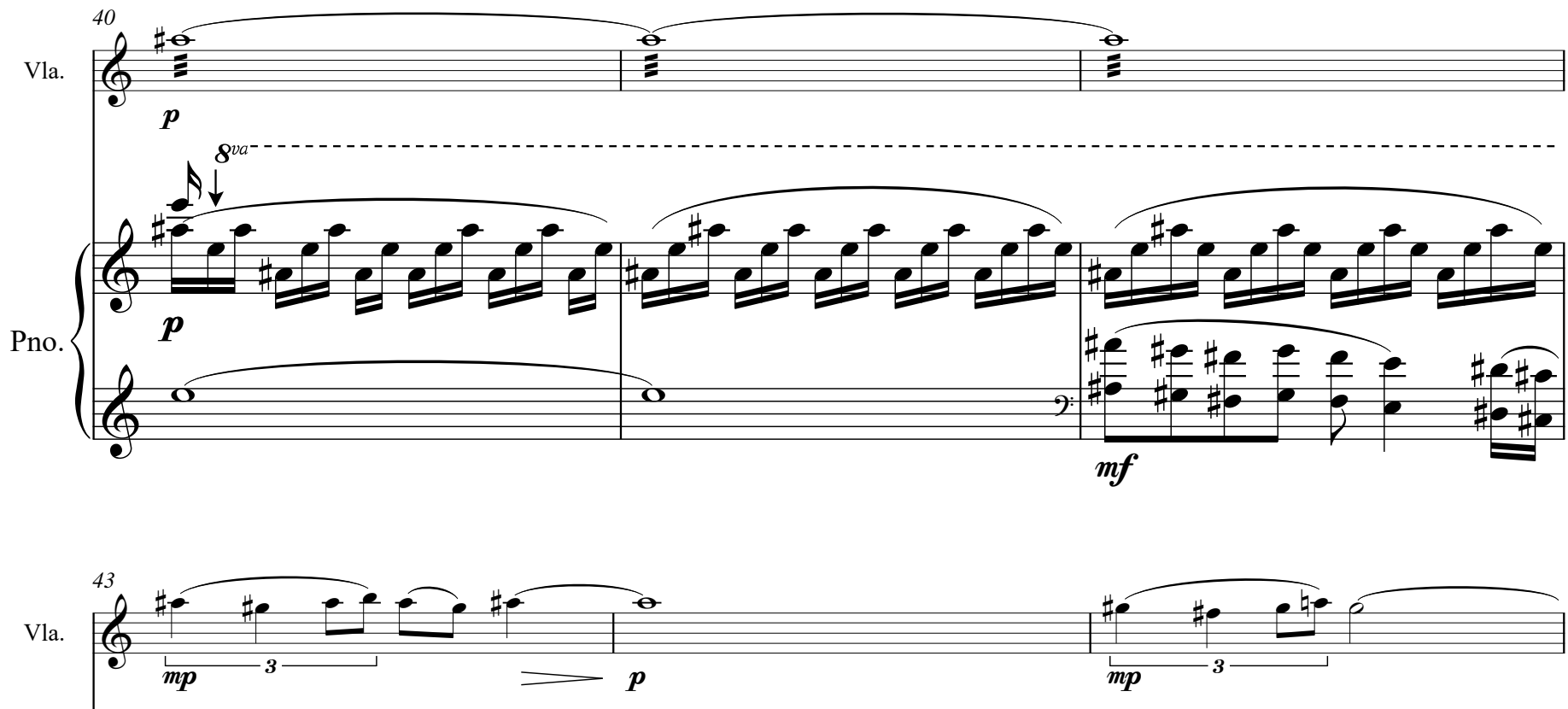

(8)
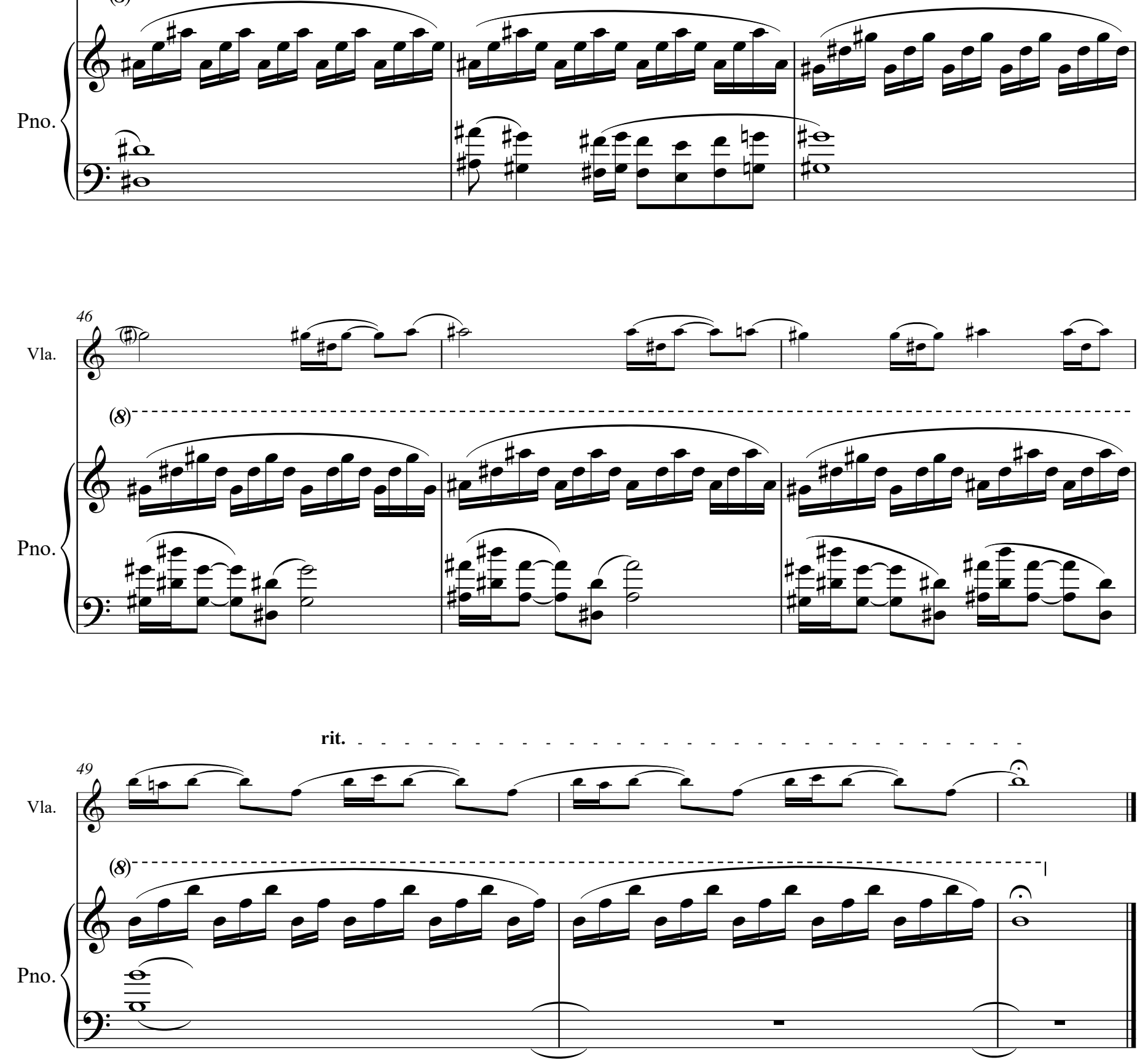


\section{III.}
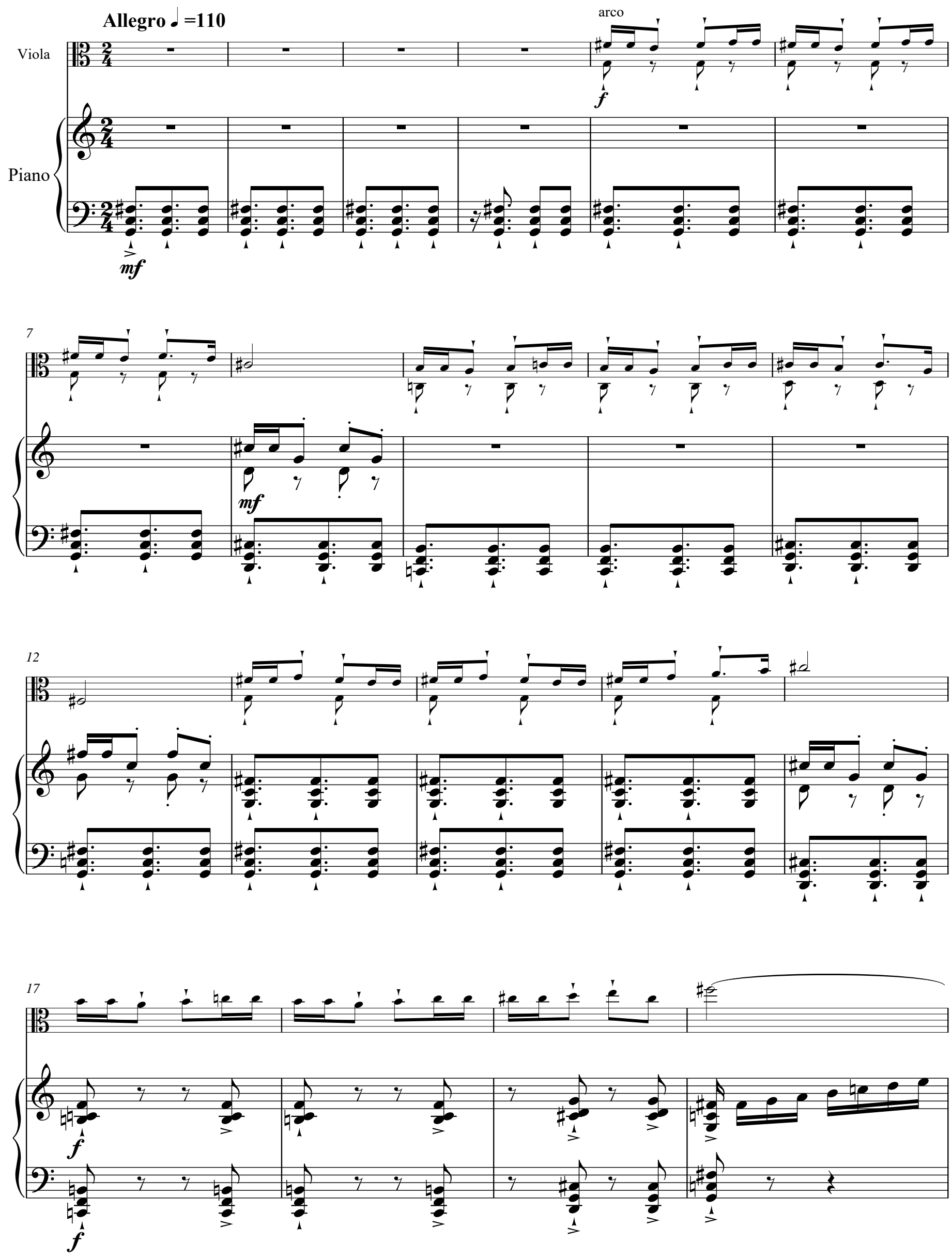
14

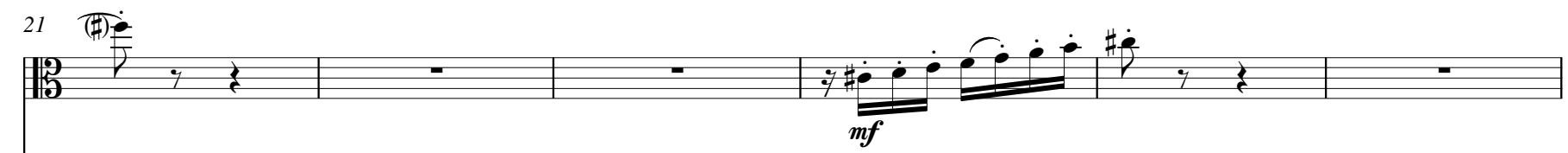

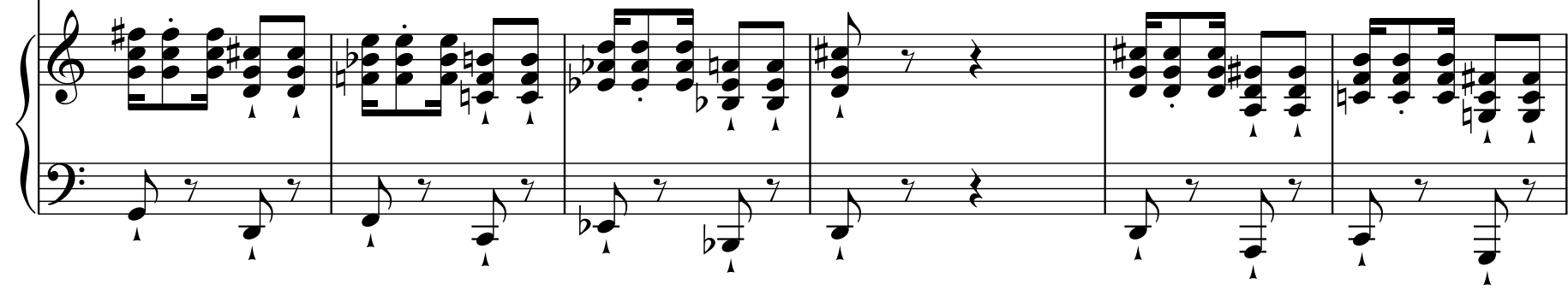

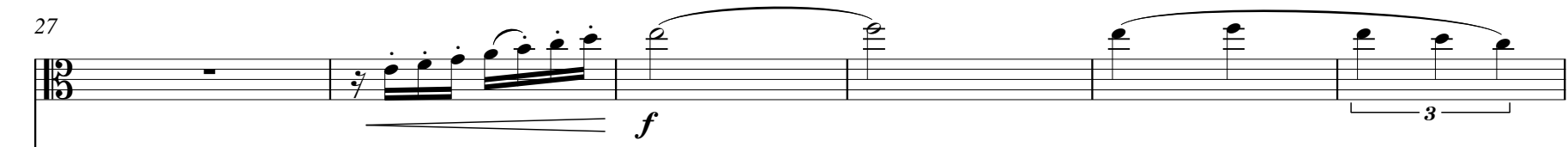

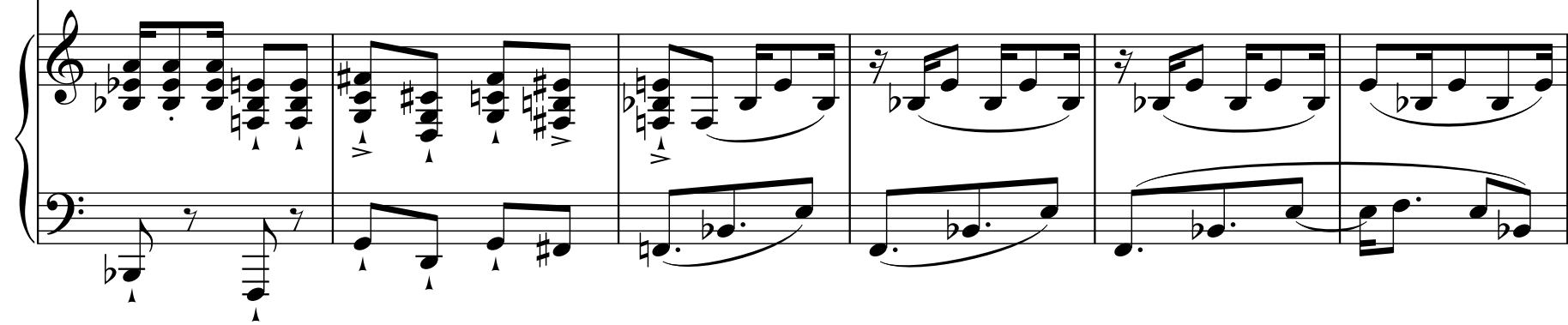
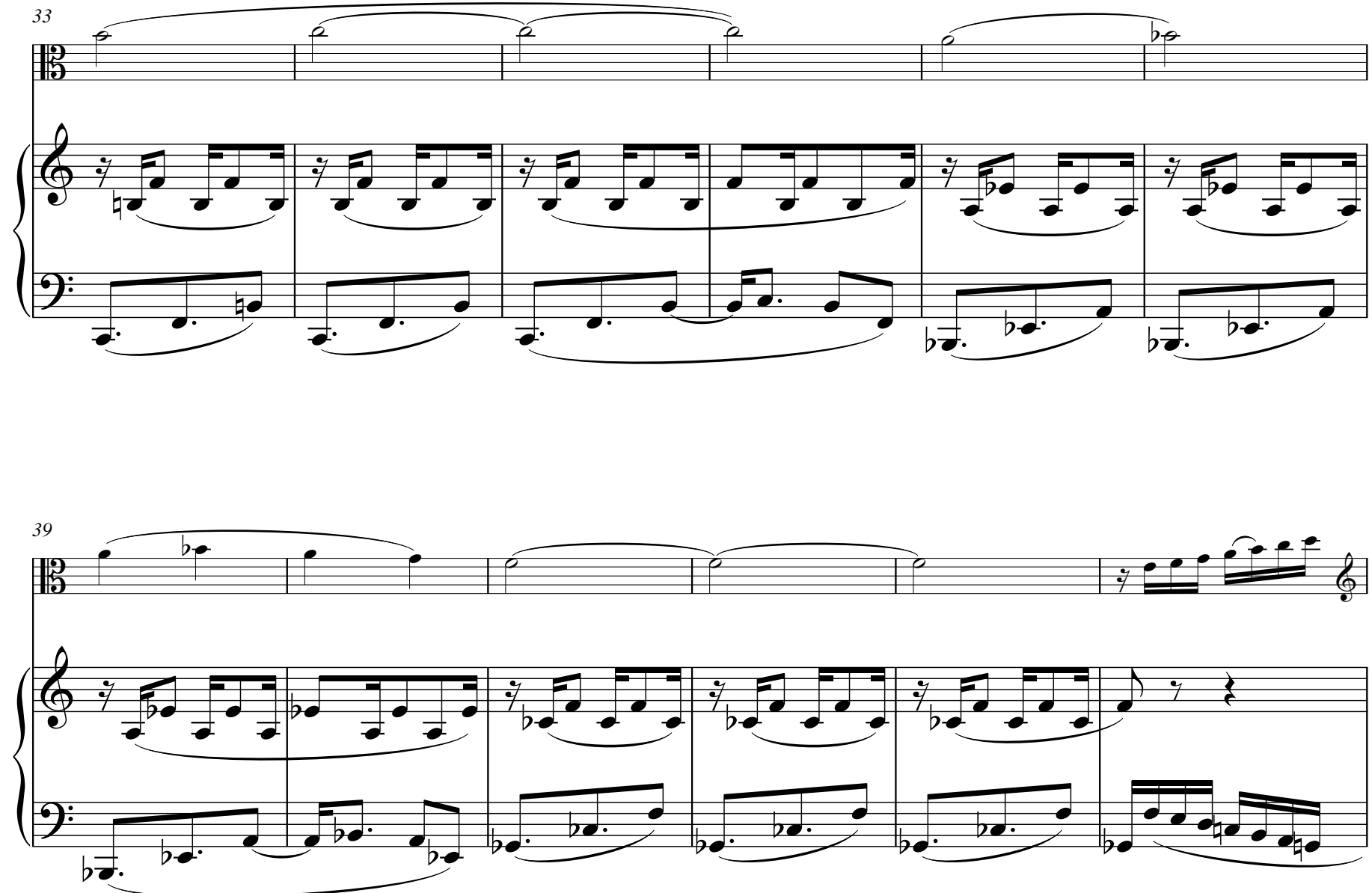
Pablo Louder. Tres piezas para viola y piano

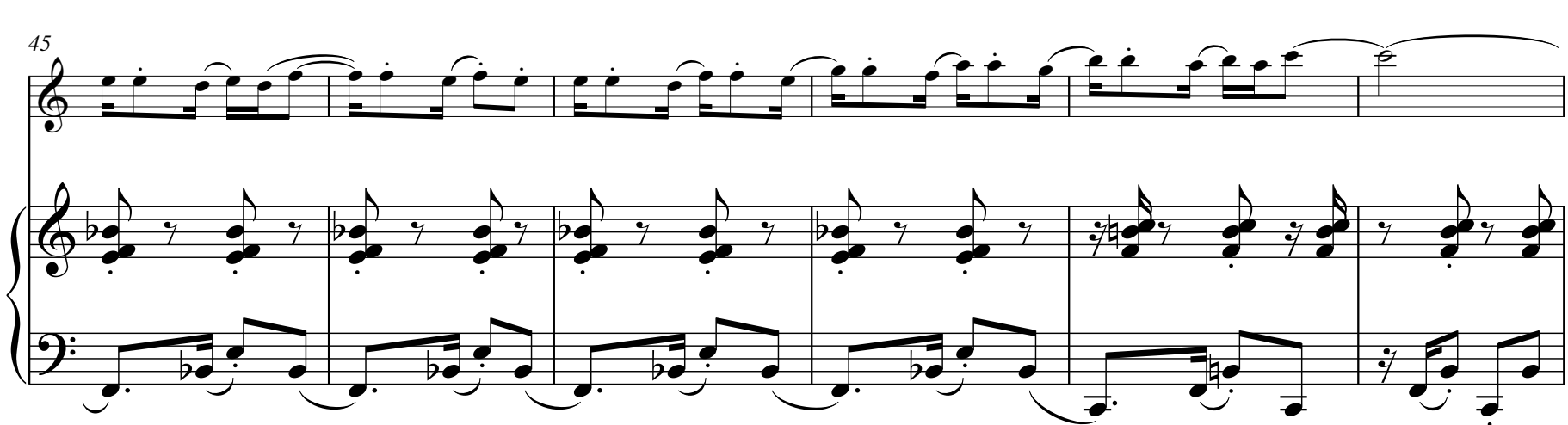
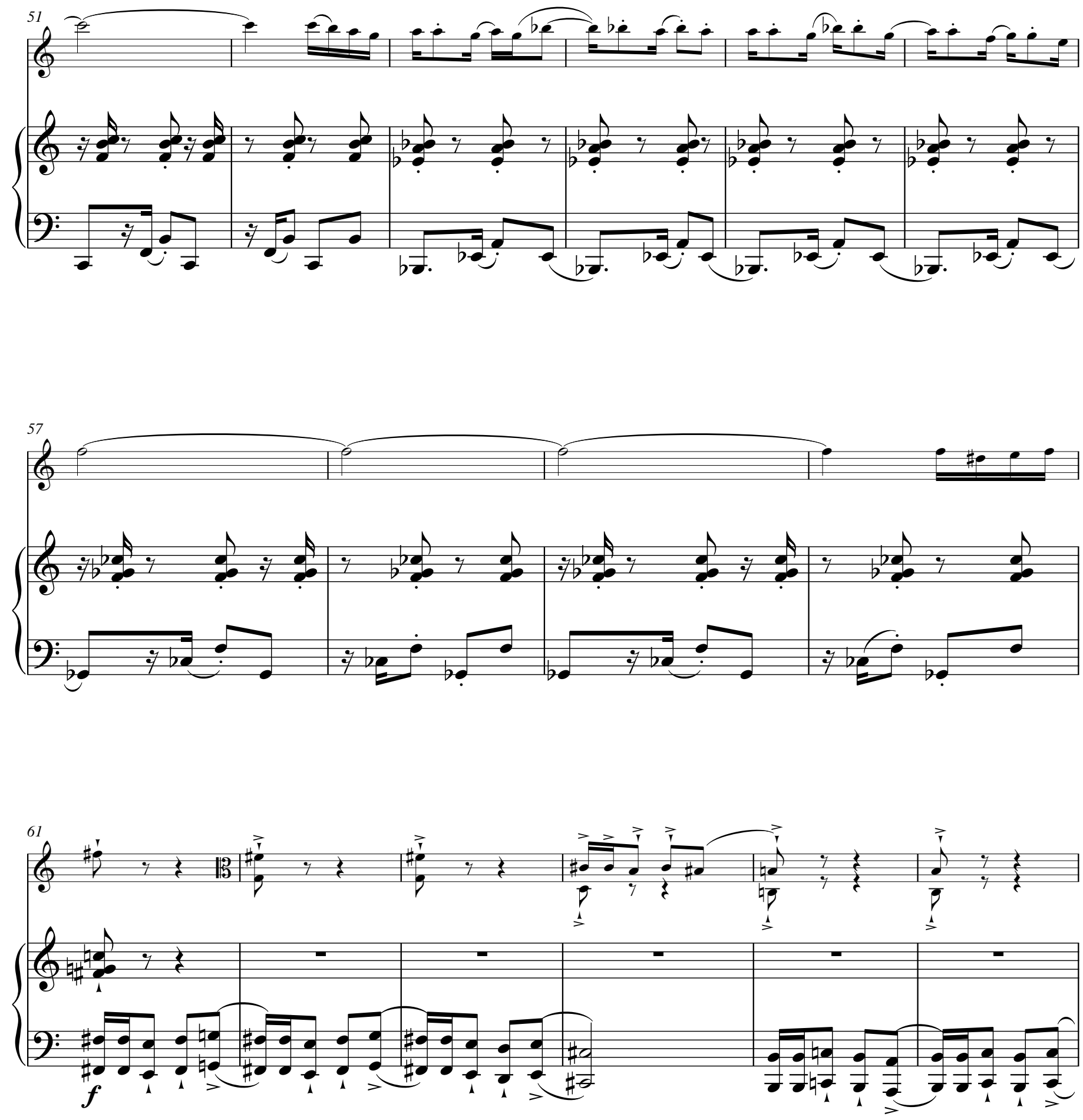
16

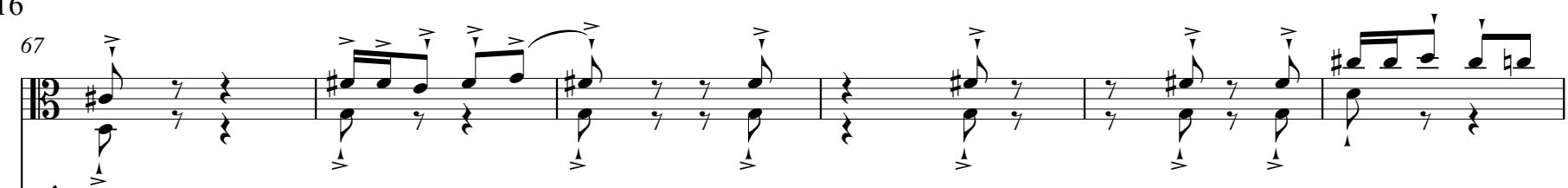

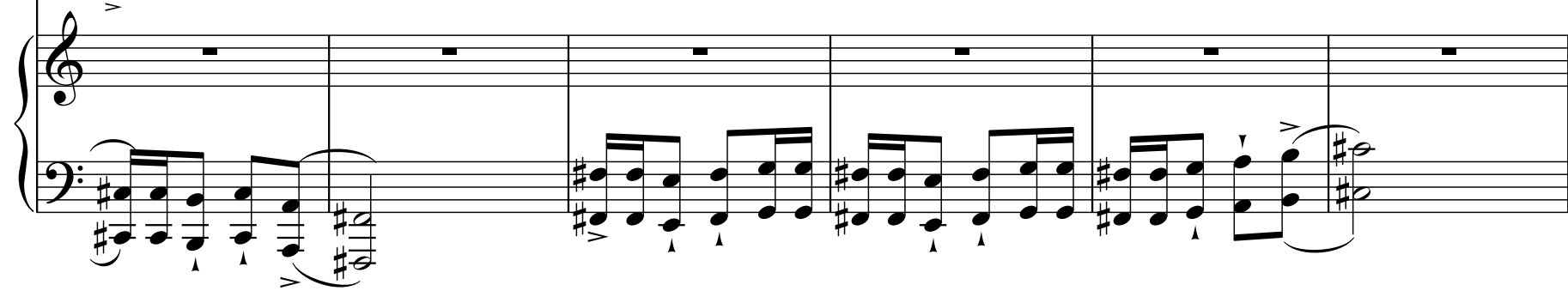
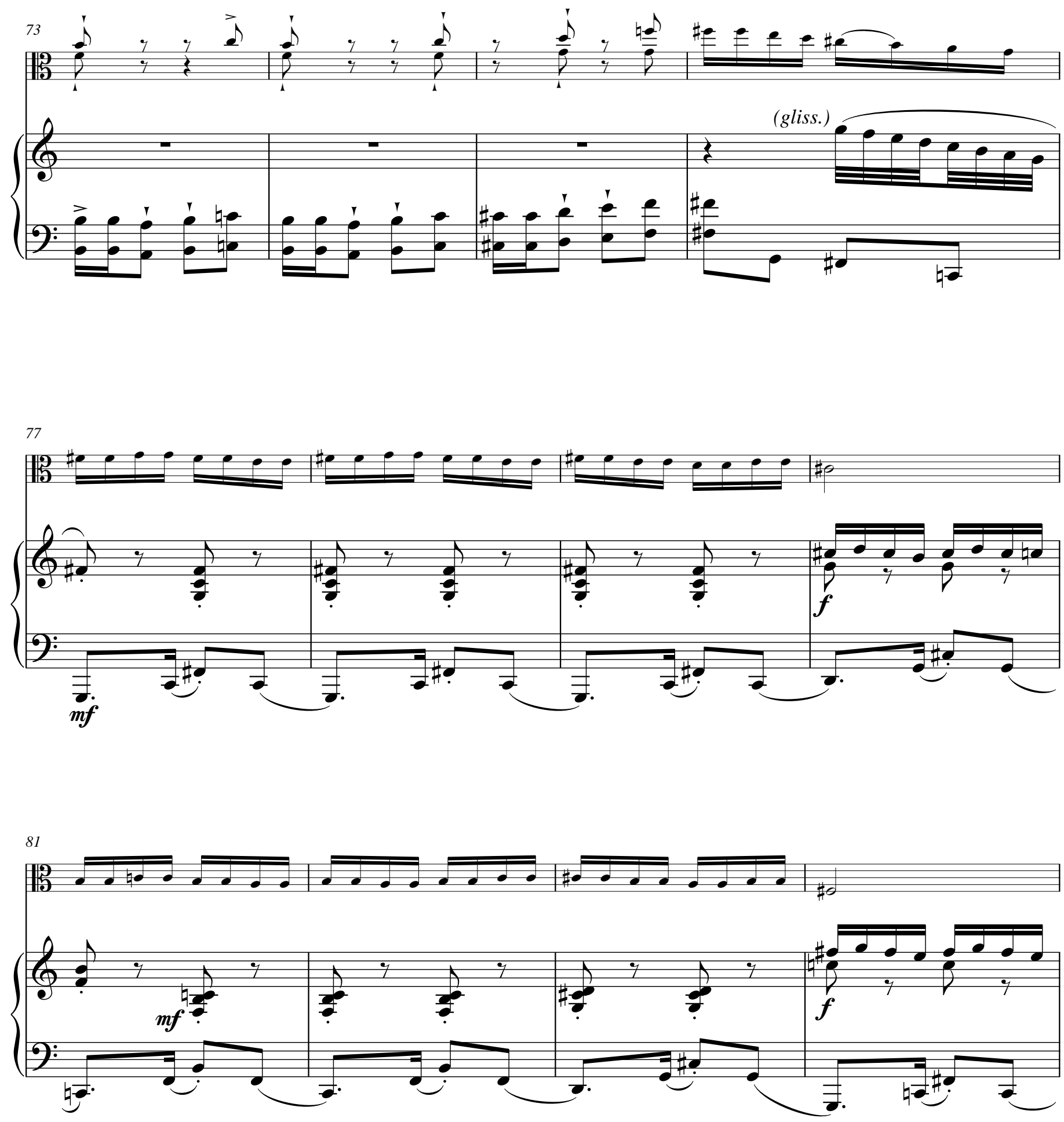

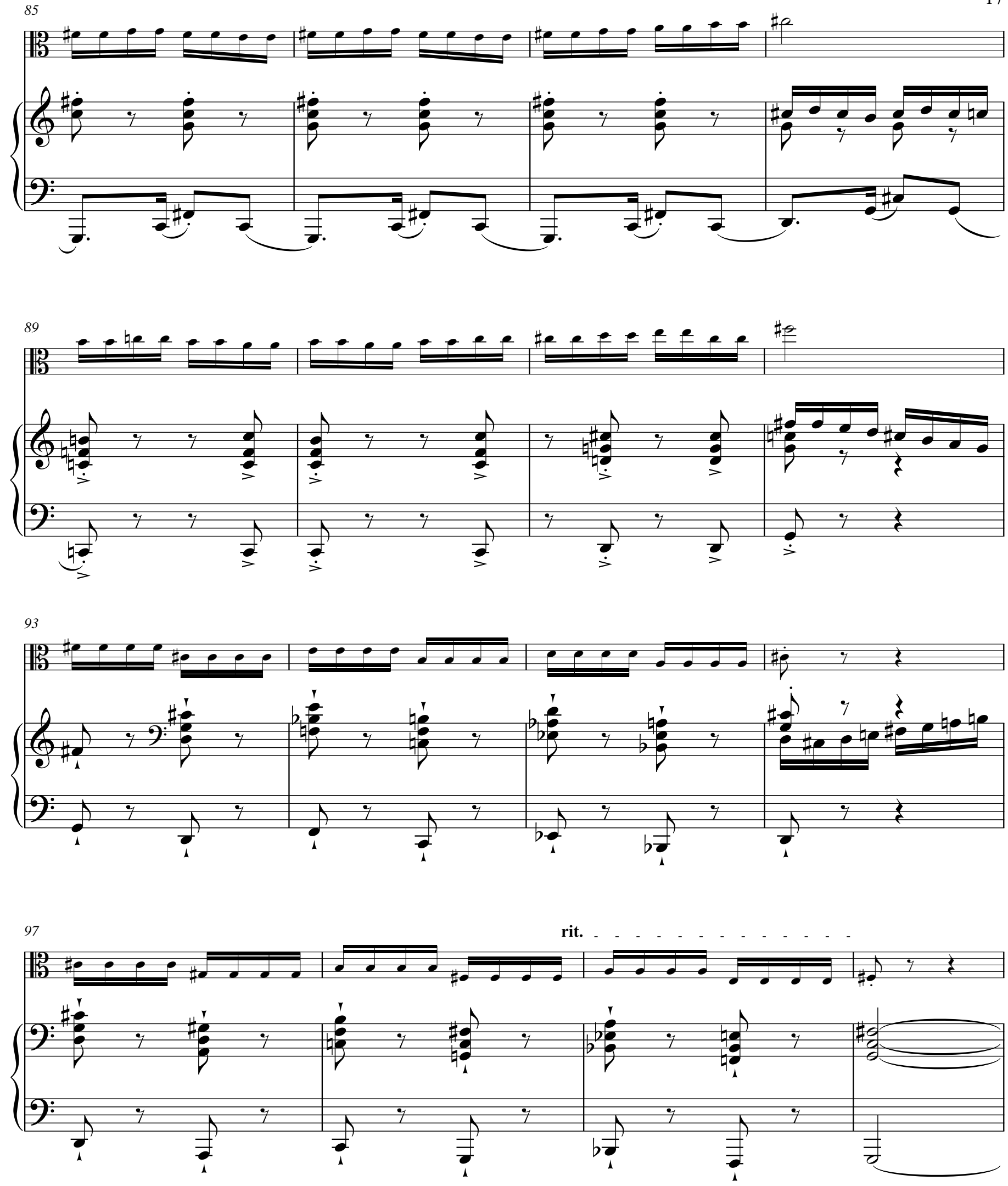

rit. -

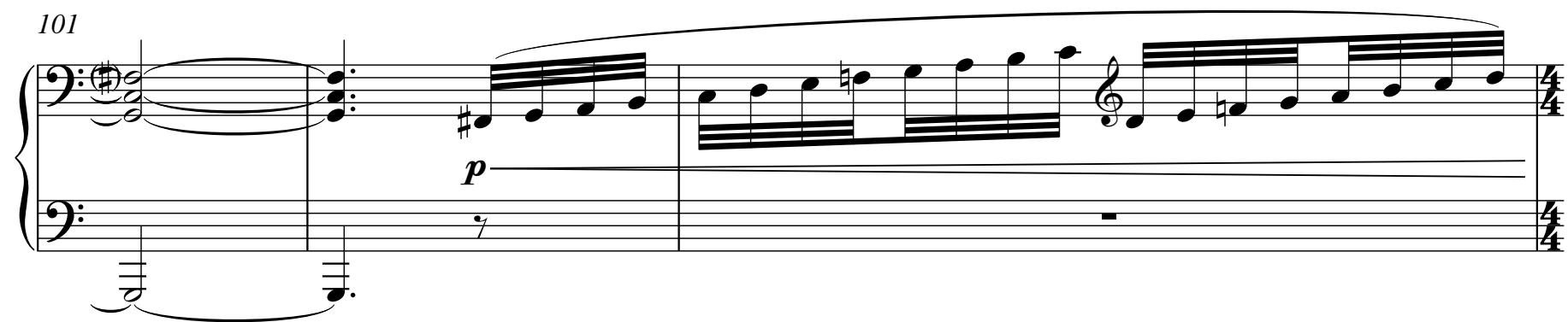



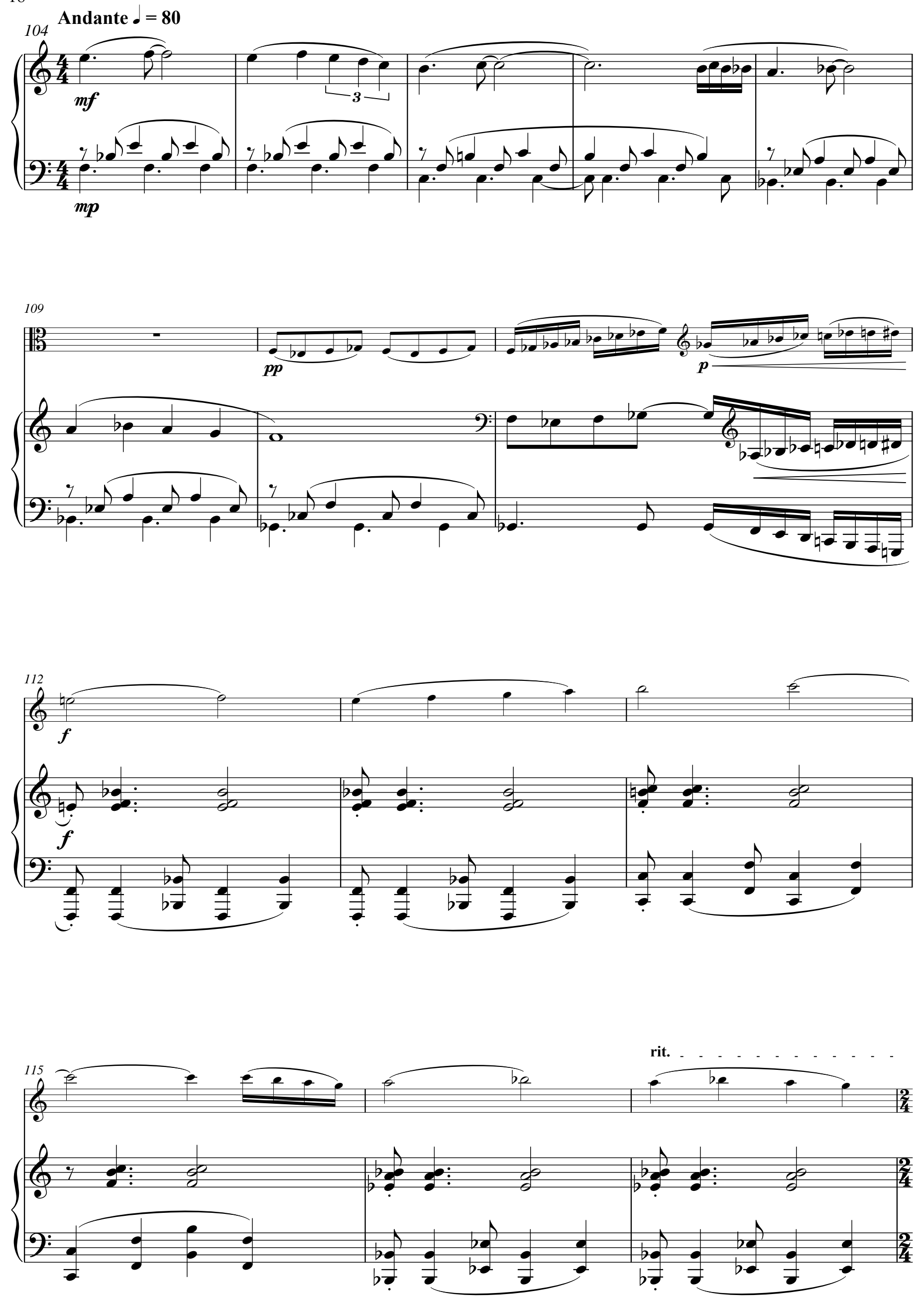
Allegro $\downarrow=120$
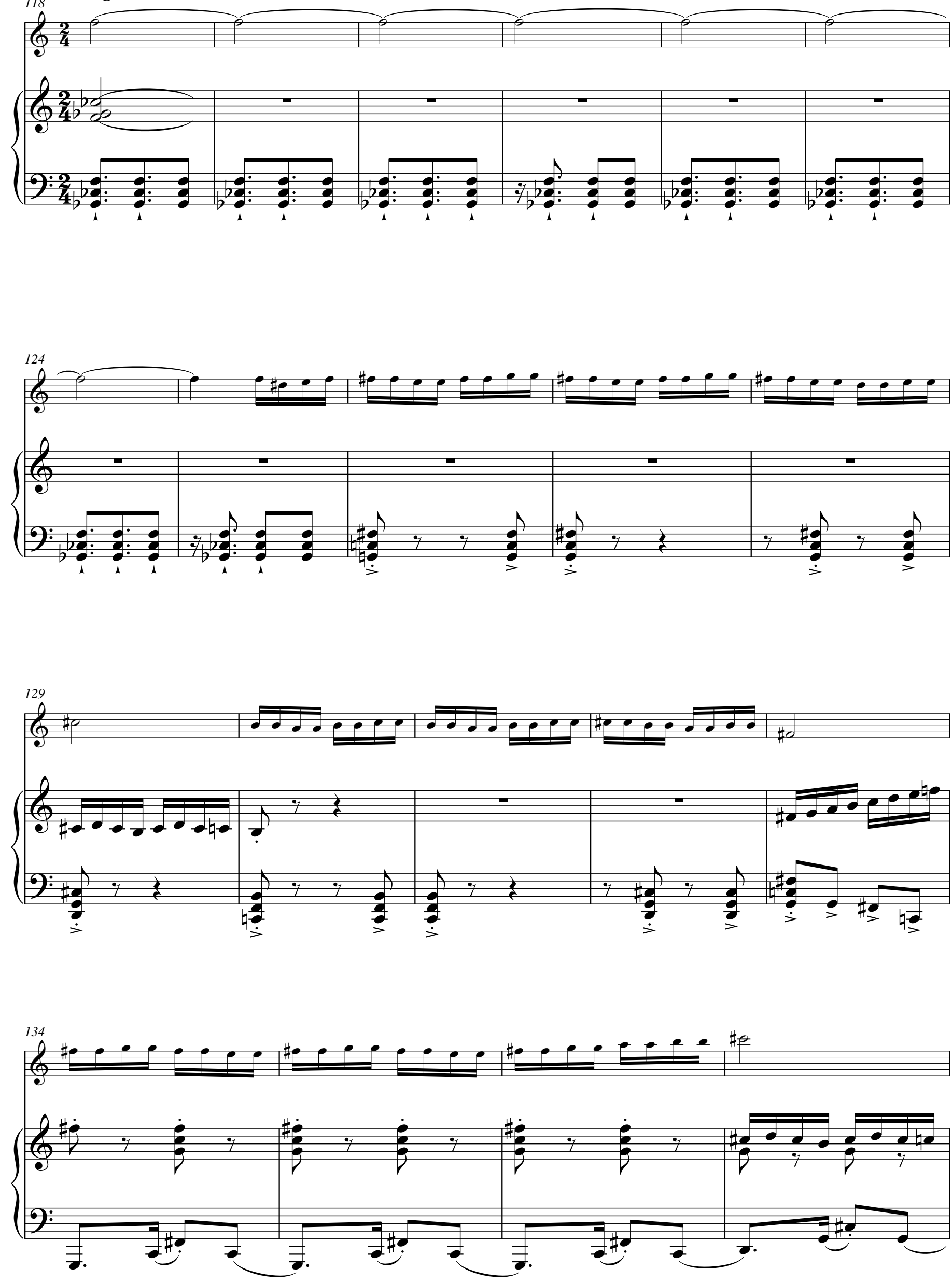

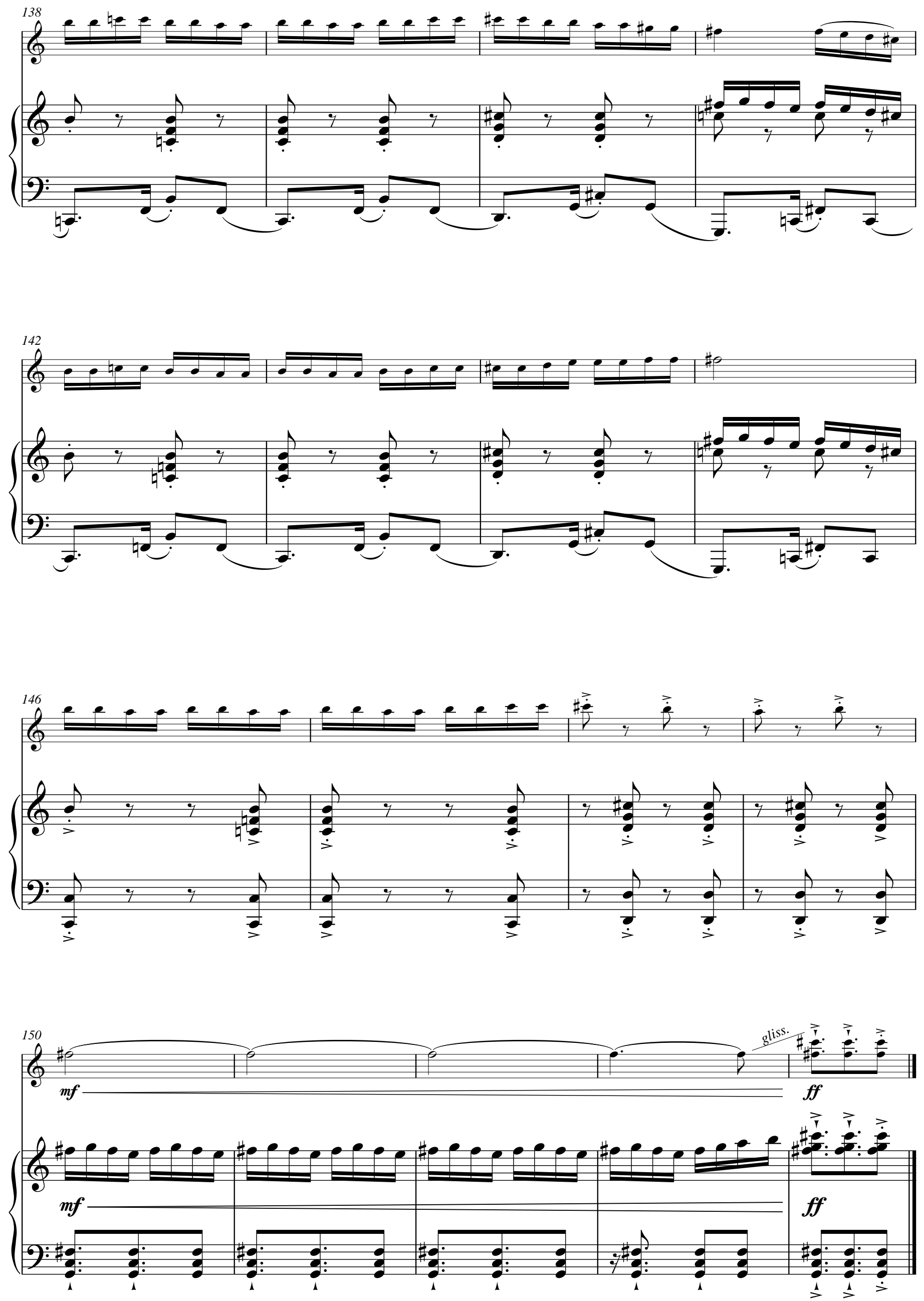

CC BY-NC-SA 